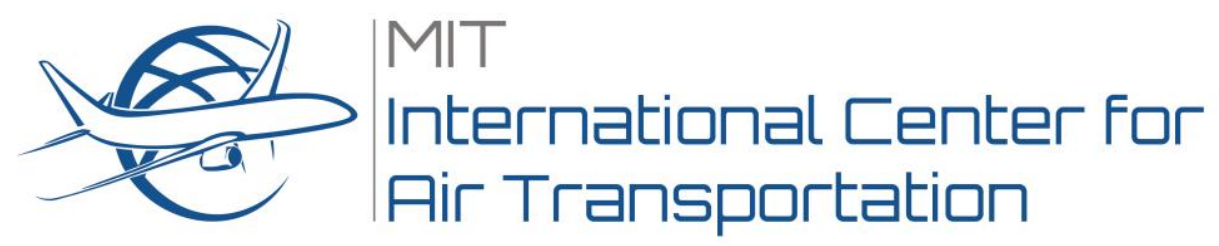

\title{
FEASIBILITY STUDY OF SHORT TAKEOFF AND LANDING URBAN AIR MOBILITY VEHICLES USING GEOMETRIC PROGRAMMING
}

\author{
Christopher Courtin, Michael Burton, Patrick Butler, Alison Yu, \\ Parker D. Vascik and R. John Hansman
}

This report presents research originally published under the same title at the $18^{\text {th }}$ AIAA Aviation Technology, Integration, and Operations Conference in Atlanta, GA. Citations should be made to the original work with DOI: https://doi.org/10.2514/6.2018-4151

Report No. ICAT-2018-06

June 2018

MIT International Center for Air Transportation (ICAT)

Department of Aeronautics \& Astronautics

Massachusetts Institute of Technology

Cambridge, MA 02139 USA 


\title{
Feasibility Study of Short Takeoff and Landing Urban Air Mobility Vehicles using Geometric Programming
}

\author{
Christopher Courtin; Michael Burton† Patrick Butler; Alison Yu, Parker Vascik, John Hansman" \\ Massachusetts Institute of Technology, Cambridge, 02139, USA
}

Electric Short Takeoff and Landing (eSTOL) vehicles are proposed as a path towards implementing an Urban Air Mobility (UAM) network that reduces critical vehicle certification risks and offers advantages in vehicle performance compared to the widely proposed Electric Vertical Takeoff and Landing (eVTOL) aircraft. An overview is given of the system constraints and key enabling technologies that must be incorporated into the design of the vehicle. The tradeoffs between vehicle performance and runway length are investigated using geometric programming, a robust optimization framework. Runway lengths as short as 100-300 $\mathrm{ft}$ are shown to be feasible, depending on the level of technology and the desired cruise speed. The tradeoffs between runway length and the potential to build new infrastructure in urban centers are investigated using Boston as a representative case study. The placement of some runways up to $600 \mathrm{ft}$ is shown to be possible in the urban center, with a significant increase in the number of potential locations for runways shorter than 300ft. Key challenges and risks to implementation are discussed.

\section{Nomenclature}

$\begin{array}{ll}A & \text { takeoff helper variable } \\ A R & \text { wing aspect ratio } \\ \text { ATC } & \text { air traffic control } \\ b & \text { wing span } \\ B & \text { takeoff helper variable } \\ c & \text { wing local chord } \\ \bar{c} & \text { mean aerodynamic chord } \\ C_{D} & \text { drag coefficient } \\ C D A & \text { area drag coefficient } \\ C_{D_{g}} & \text { ground drag coefficient } \\ c_{d_{p}} & \text { wing profile drag coefficient } \\ C_{E} & \text { jet kinetic energy coefficient } \\ C_{J} & \text { jet momentum coefficient } \\ C_{L} & \text { lift coefficient } \\ C_{L_{g}} & \text { ground lift coefficient } \\ C_{L_{\text {max }}} & \text { max lift coefficient } \\ C_{T} & \text { thrust coefficient } \\ C_{X} & \text { streamwise force coefficient } \\ \text { CTOL } & \text { conventional take off and landing } \\ D & \text { drag } \\ D_{C} & \text { drag due to circulation } \\ D_{P} & \text { profile drag } \\ D_{T} & \text { drag due to jet turning }\end{array}$

$\begin{array}{ll}D_{\text {Prop }} & \text { Propeller diameter } \\ \text { DEP } & \text { distributed electric propulsion } \\ e & \text { span efficiency } \\ f_{\text {struct }} & \text { structural weight fraction } \\ F_{J} & \text { jet force } \\ g & \text { gravitational constant } \\ \text { GP } & \text { geometric programming } \\ h_{\text {batt }} & \text { specific battery energy } \\ h_{j} & \text { jet height } \\ L & \text { lift } \\ L_{C} & \text { lift due to circulation } \\ L_{J} & \text { normal component of the jet force } \\ m_{J} & \text { jet mass flow } \\ \mathcal{M}_{\text {root }} & \text { root bending moment } \\ N & \text { deceleration factor } \\ N_{\text {pax }} & \text { number of passengers } \\ P_{\text {shaft-max }} & \text { max shaft power } \\ (P / W)_{\text {motor }} & \text { motor specific power } \\ R & \text { vehicle range } \\ R e & \text { Reynolds number } \\ S & \text { wing area } \\ S_{\text {land }} & \text { landing ground roll } \\ S_{\text {runway }} & \text { runway distance } \\ & \end{array}$

\footnotetext{
${ }^{*}$ Graduate Student, Aeronautics and Astronautics Engineering, MIT, 77 Mass Ave, Cambridge MA, 02139, AIAA Student. ${ }^{\dagger}$ Graduate Student, Aeronautics and Astronautics Engineering, MIT, 77 Mass Ave, Cambridge MA, 02139, AIAA Student. ${ }^{\ddagger}$ Graduate Student, Aeronautics and Astronautics Engineering, MIT, 77 Mass Ave, Cambridge MA, 02139, AIAA Student. $\S$ Graduate Student, Aeronautics and Astronautics Engineering, MIT, 77 Mass Ave, Cambridge MA, 02139, AIAA Student. TGraduate Student, Aeronautics and Astronautics Engineering, MIT, 77 Mass Ave, Cambridge MA, 02139, AIAA Student.

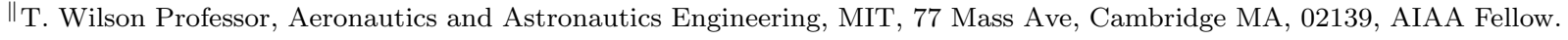




$\begin{array}{llll}S_{\text {TO }} & \text { take off ground roll } & W_{\text {motor }} & \text { motor weight } \\ \text { STOL } & \text { short take off and landing } & W_{\text {MTO }} & \text { max take off weight } \\ S_{y_{\text {spar }}} & \text { spar section modulus } & W_{\text {pax }} & \text { passenger weight } \\ t & \text { flight time } & W_{\text {skin }} & \text { wing skin weight } \\ T & \text { thrust } & W_{\text {spar }} & \text { wing spar weight } \\ \text { TOLA } & \text { takeoff and landing area } & W_{\text {struct }} & \text { structural weight } \\ \text { UAM } & \text { urban air mobility } & W_{\text {wing }} & \text { wing weight } \\ V & \text { speed } & W / S & \text { wing loading } \\ V_{\text {cruise }} & \text { cruise speed } & \alpha & \text { angle of attack } \\ V_{J} & \text { jet velocity } & \alpha_{i_{\infty}} & \text { far field induced downwash angle } \\ V_{\text {min }} & \text { minimum cruise speed } & \delta_{f} & \text { flap/jet initial deflection from chord line } \\ V_{\text {TO }} & \text { takeoff speed } & \eta_{\text {elec }} & \text { combined electric efficiency } \\ V_{\text {TD }} & \text { touch down speed } & \eta_{\text {prop }} & \text { propeller efficiency } \\ V_{\text {stall }} & \text { stall speed } & \gamma & \text { flight path angle } \\ V_{\infty} & \text { free stream velocity } & \mu & \text { rolling friction coefficient } \\ \text { VFR } & \text { visual flight rules } & \rho & \text { air density } \\ \text { VTOL } & \text { vertical take off and landing } & \sigma_{\text {CFRP }} & \text { carbon fiber allowable stress } \\ W_{\text {batt }} & \text { battery weight } & & \\ W_{\text {fadd }} & \text { additional wing weight } & & \end{array}$

\section{Introduction}

Within the aviation industry there is a strong and growing interest in the development of Urban Air Mobility (UAM) networks, which are aerial transportation systems in and around major metropolitan areas. The defining features of UAM networks are fleets of relatively small vehicles operating off a distributed network of Takeoff and Landing Areas (TOLAs) located within dense urban centers, primarily focused on passenger transport. Past efforts at developing UAM networks based on helicopters were largely unsuccessful due to the high costs of helicopter operations, the high levels of noise generated, and the poor safety record of these aircraft[1]. Recent advances in electric vehicle propulsion and key subsystem technologies have opened the door to new vehicle configurations that may mitigate these fundamental challenges. The ride-sharing operational models that have been successfully developed for ground transportation also have the potential to improve the economics of UAM operations through pooling and on-demand service. This has sparked renewed interest in the UAM concept, and there are currently many aircraft manufacturers building or flighttesting UAM-specific aircraft. The majority of these vehicles are based on eVTOL (electric Vertical and Takeoff Landing) configurations, mainly because they do not require large runways and have less mechanical complexity than conventional helicopters.

Any proposed UAM system is exposed to many sources of risk, such as local noise regulations, ATC capacity concerns, pilot or automation availability, infrastructure availability, and uncertain market demand[1][2]. Additional risk arises from the need to get novel vehicle designs through the FAA certification process. Historically, certifying novel types of aircraft has been a difficult and time-consuming process. The AugustaWestland AW609 tiltrotor is a good example of this. The target date for typed certification has been delayed from 2007 to 2019[3]. The authors propose that using a short takeoff and landing (STOL) fixedwinged configuration reduces the risk associated with the certification process and a STOL aircraft would be feasible for UAM operations.

Certification risk arises from the potential for catastrophic vehicle failures and the complexity of required mitigations. For eVTOL aircraft, certification risk arises from the potential failure of three critical systems common to all configurations: 1) the active flight stabilization system that controls vehicle attitude and lift during the vertical and translational phases of flight via differential thrust 2) the power delivery system that supplies power from the batteries to the motors and the motors themselves and 3) the batteries that store electrical power. The risk of thermal runaway in lithium-polymer batteries is especially significant. The loss of power is also a higher-consequence hazard than for existing aircraft because in most eVTOL configurations a loss of power results in a loss of control. A more complete discussion is provided in [4].

For all three hazards listed above, potential mitigations in the form of highly redundant safety systems (triple-redundant flight control and power distribution architectures, for example) or physical battery containment add significantly to the vehicle weight and/or cost. The need to mitigate multiple high-consequence hazards via complex systems also adds difficulty to the certification process and increases the expected timeline for initial UAM operations. 
The advantage of a STOL fixed wing configuration is that it is not exposed to several of these critical hazards; it does not require a complex fly-by-wire system and can maintain attitude control in the event of a loss of thrust. For an early entrant to the UAM market, the use of STOL presents a lower-risk pathway towards implementing a useful capability.

STOL aircraft also have performance advantages compared to VTOL aircraft, since they need less power to become airborne and hence have much lighter power systems. This translates to higher payloads, longer ranges, or smaller aircraft. There are also potential noise benefits; a fixed-wing aircraft requires less power/weight and has fewer noise-producing mechanisms than a rotorcraft[5]. However, noise generated depends strongly on the details of propeller design and further work would be required to accurately assess the noise impact of this type of vehicle.

The clear downside of STOL aircraft for UAM is they require a runway of some length, which impacts the amount of infrastructure required to build a TOLA. In dense urban areas, availability of infrastructure is severely limited. If no runways can be placed in useful locations, or the runways that can be placed are too short for feasible vehicles, then any certification and performance advantages of STOL vehicles are immaterial.

The purpose of this paper is to assess the feasibility of a UAM system that features STOL aircraft from both the vehicle and infrastructure perspective. The tradeoff between runway length and high-level vehicle metrics (weight, speed, range, and payload) is shown, as well as the tradeoff between runway length and the availability of potential TOLA locations in a dense urban center. The ultimate goal is to determine whether a STOL aircraft, with some useful operational capability, can be made to land on a runway short enough to place in an urban environment. As part of this work, previous literature concerning small aircraft transportation system design [6],[7], thin-haul transportation vehicles[8],[9],[10], VTOL aircraft[11], and STOL aircraft is considered[12],[13].

\section{Vehicle Requirements Definition}

To perform a feasibility study of this new class of aircraft, the high-level vehicle requirements (range, speed, payload, and takeoff/landing distance) must be established, which arise from the projected use case of UAM vehicles. The clearest need for an urban air mobility system arises from the traffic problem that plagues most major metropolitan areas. Large numbers of people travel into and out of the urban center every day, creating massive surface congestion that extends for miles outside of the city. To be an effective alternative to ground transportation, a UAM vehicle must have sufficient range to bypass this congestion, and preferably be located near the homes of the commuting population, as well as speed that offers significant time savings over an automobile.

To estimate the range and speed requirements for a UAM vehicle, three representative US cities were considered; Boston, Dallas, and Los Angeles. In order to bypass the surface congestion surrounding the city, the aircraft must have a range of at least $50 \mathrm{nmi}$. If the range is further increased to $100 \mathrm{nmi}$, then the majority of commuters become accessible. Therefore a range of $100 \mathrm{nmi}$ was determined as the baseline range requirement. The baseline cruise speed requirement is $100 \mathrm{kts}$ in order to allow for significant time savings compared to ground transportation, which is especially true for situations with traffic.

The payload requirements for the vehicle are derived from the need to carry both a pilot (in initial operations) as well as a sufficient number of passengers. Uber and others have shown there to be a potential market for vehicles carrying only a pilot and a single passenger, but that more passengers improves the economic viability of the concept[2]. This is especially true in early operations before widespread vehicle automation, where the number of pilots is likely to be limited by pilot availability, and the number of vehicle operations may be limited by ATC constraints. Both of these factors favor more passengers per aircraft. The number of passengers on board is also expected to trade with vehicle size, and hence required runway length. Therefore, for this study there is a minimum requirement of at least one pilot and one passenger, to provide a common baseline with VTOL concepts. A key goal is to determine how required runway length scales as the number of passengers are increased. The design mission for this feasibility study is summarized in Table 1. This is similar to the design missions proposed for other UAM vehicles[2][12]. These requirements form the basis of the vehicle design space exploration conducted in Section IV to determine how short of a runway is feasible, while not violating the high-level vehicle requirements.

The takeoff and landing distance requirement is highly dependent on the available infrastructure. GIS building footprint data was analyzed in order to understand how available building infrastructure varies with 
runway length. Compared to highways and railways, over water locations, and ground locations, buildings are the type of STOLport location most dependent on runway length. GIS data provides the footprints of buildings in a city[14][15]. Based on this GIS data, if at least one side of the building footprint was as long as a given runway length, then the footprint was counted as a possible building. Figure 1 shows data trends of possible buildings as a function of runway length in order to provide insight into the manner in which the number of available buildings varies with runway length. For runway lengths of 500 feet or less, the determined baseline vehicle requirement, it is feasible to place STOLports within an urban center; while reducing the runway length to 300 feet or below exponentially increases the number of potential locations. Once runway lengths become shorter than $100 \mathrm{ft}$, the differences in infrastructure requirements relative to a helipad become very minor.
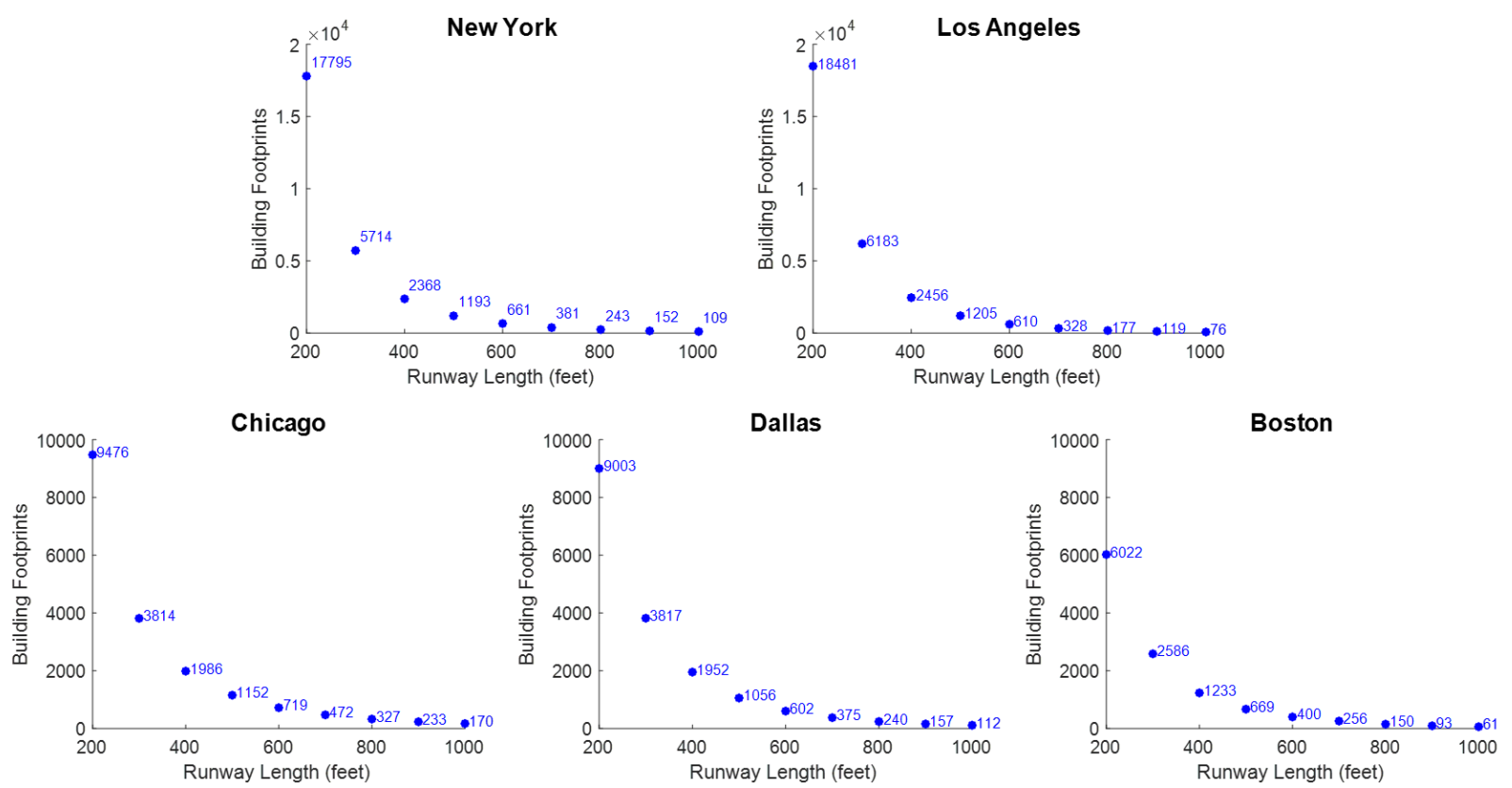

Figure 1: Available STOLport placement options versus runway length for five US cities

Table 1: Design Mission

\begin{tabular}{lc}
\hline \hline Parameter & Value \\
\hline Range & $100[\mathrm{nmi}]$ \\
Cruise Speed & $\geq 100[\mathrm{kts}]$ \\
Crew & 1 \\
Passengers & $1+$ \\
Takeoff/Landing Distance & $\leq 500[\mathrm{ft}]$ \\
\hline
\end{tabular}

In order to gain an understanding of the existing aircraft infrastructure within urban centers, Boston, Dallas, and Los Angeles were again analyzed. Currently existing aircraft infrastructure for either VTOL or STOL within urban centers is very limited, and the infrastructure that does exist is often reserved for medical uses or is unsuitable for UAM missions. Therefore if significant new infrastructure requirements will be necessary to make any UAM vision a reality, then the feasibility of the STOL UAM concept rests strongly on the runway lengths that are achievable.

At high network densities, the effects of approach path constraints on potential infrastructure locations require further investigation. Local and federal regulations on building runways on top of pre-existing infrastructure should also be considered, as well as the cost of placing new infrastructure in an urban core. 
The required network density to reliably handle crosswinds is currently uncertain, and is likely to vary from city to city based on the prevalent local wind conditions.

\section{Vehicle Design Considerations and Key Enabling Technologies}

STOL aircraft make design compromises compared to CTOL aircraft in order to achieve short-field performance, the significance of which increase as the required runway length becomes shorter. This section will discuss some of the key vehicle-level trades involved in designing an aircraft for short-field performance, and will discuss some of the ways that emerging electric aircraft technologies will offer improved performance over historical vehicles.

Short Takeoff and Landing Considerations At a high level, the runway a vehicle operates off of must be equal to the larger of either the takeoff or landing distances. To reduce the takeoff distance, the vehicle design can be changed such that it reaches the liftoff speed faster by increasing the thrust, or the liftoff speed can be lower by decreasing the wing loading $W / S$ or by increasing the wing $C L_{\text {max }}$. These changes may also serve to increase the climb angle $\gamma_{\text {climb }}$, which is desirable to minimize the time spent at low altitude and to clear nearby obstacles in the urban setting.

Decreased $W / S$ and increased $C L_{\max }$ also help reduce the landing distance, since they reduce the touchdown speed $V_{T D}$. Additionally, the landing distance may be shortened by increasing the drag after touchdown, either by wheel brakes, aerodynamic braking, or reverse thrust.

For these reasons, compared to conventional takeoff and landing (CTOL) aircraft of the same size, STOL vehicles tend to be more lightly wing loaded, have high power-to-weight ratios, and have large and complex high-lift systems to maximize $C L_{\max }$. To first order, high power-to-weight ratios and complex high-lift systems both add significant weight to the system, with second-order penalties on efficiency. For a given aircraft, decreasing wing loading below its optimal value will limit the top speed of the vehicle, as well as making it more sensitive to wind gusts. It will also increase the power required to cruise at a given speed, requiring additional fuel or batteries, or reducing range. For these reasons, and since short field capability is not required at most airports, STOL aircraft have not been widely adopted outside of the bush pilot community.

The introduction of new electric aircraft technologies offer a variety of potential improvements over existing STOL aircraft, giving them significant advantages both in the UAM market and relative to current STOL vehicles. This is similar to the way these technologies are being proposed to change vertical flight. The following are the key technologies that are considered for an electric STOL (eSTOL) aircraft. The impact of each technology will be assessed at a conservative baseline level, as well as a more aggressive advanced level to show the potential impact of technological improvements.

Distributed Electric Propulsion DeP is a collection of enabling technologies (high specific energy batteries, electric motors and controllers) that enable the replacement of a few large propulsors with many smaller ones. The NASA X-57 shown in Figure 2 is an example of a fixed-wing DEP configuration currently being developed. This novel propulsion system architecture allows optimization of different parts of the propulsion system for different phases of flight, which increases overall efficiency. It also increases system redundancy, and most importantly for this application increases the effectiveness of the wing through blown lift (discussed below). From a modeling perspective, it also allows cruise efficiency to be treated independently of takeoff power. References [17] and [18] discuss the benefits of DEP in more detail.

High Power Electric Motors Apart from their role as an enabling component of DEP, electric motors have two other useful capabilities for electric aircraft. The first is the ability to be operated at power settings significantly higher than maximum continuous power for short periods of time. Since high power is most important for a short time at takeoff, this effect could significantly minimize the weight penalty of a highpower propulsion system[19]. Additionally, the rotation direction of these motors can be electrically reversed. This is useful on braking to provide reverse thrust at touchdown, which shortens landing distance without the weight penalty of dedicated thrust reversal systems.

Advanced Flight Controls Autoland systems, which allow highly repeatable and precise landings, have become ubiquitous on commercial aircraft and have been proposed for emergency use in GA aircraft as well[20]. In this context, a highly accurate autoland or landing guidance system could be used to reduce 
the margin of safety between the vehicle actual landing distance and required runway length. It could also be used to reduce the acceptable margin between landing and stall speeds.

BLOWN LifT Blown lift increases the effective wing lift coefficient through two main effects. The first is that the propeller wake modifies the circulation around the wing, increasing the overall lift of the wing for a given angle of attack as well as increasing the stall angle of attack of the wing. The second is the interaction between the propeller wake and flaps, which turns the wake downward and produce an upwards force as a result[21]. Blown lift enables substantially larger maximum lift coefficients than are achievable for typical aircraft. NASA simulations and ground tests of an X-57-like wing show that $C_{L_{\max }}$ in excess of 5.5 is possible[22][23]. Values of $C_{L_{\max }}$ greater than 8 have been measured experimentally[24], and values in excess of 10 are possible with sufficiently strong blowing[25]. However, there are limits on the amount of blowing that can be usefully deployed, which are discussed in the subsequent section.

Lithium Polymer BAtTeries Lithium polymer batteries don't offer any advantage when trying to reduce runway length;

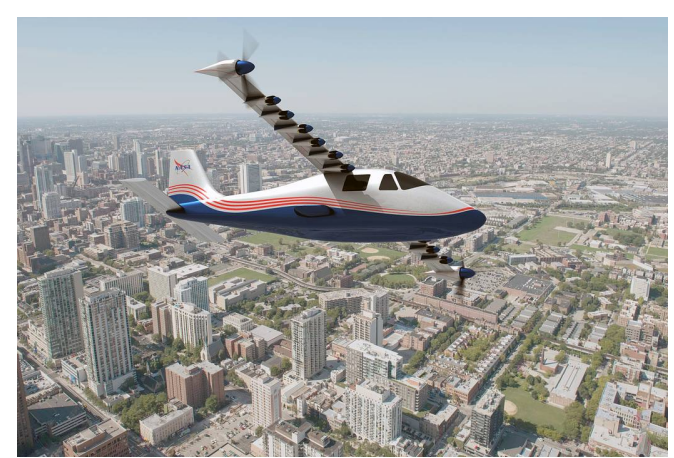

Figure 2: The NASA X-57 will demonstrate the benefits of distributed electric propulsion for fixedwing aircraft [16] in fact, they are significantly worse than a conventional reciprocating or turbine engine due to their low specific energy. However, since they are noiseless and do not generate any emissions at the vehicle level, they are an attractive option for the UAM application. For those reasons, and to provide a fair basis of comparison with eVTOL configurations, an all-electric vehicle will be assumed for this paper. A conservative estimate of battery specific energy, $150 \mathrm{Wh} / \mathrm{kg}$, was made based on commercially available high-discharge cells [26]. A more aggressive estimate of battery specific energy, $300 \mathrm{wh} / \mathrm{kg}$, was based on the projected battery specific energy requirements for commercially feasible eVTOL aircraft [27].

Table 2 summarizes the different assumptions for each key enabling technology. The basis of estimate for the achievable $C_{L_{\max }}$ via blown lift is discussed below. In this table, the maximum permissible value of $C_{L_{\max }}$ is shown; lower values may be used if advantageous on an aircraft system level, due to lower required power and hence lower. This is discussed in the following sections.

Table 2: Summary of eSTOL aircraft enabling technologies

\begin{tabular}{lll}
\hline & Baseline & Advanced \\
\hline D.E.P. & No loss of efficiency at cruise & No loss of efficiency at cruise \\
Blown Lift & $C_{L_{\max }}$ Takeoff: $\leq 6$ & $C_{L_{\max }}$ Takeoff: $\leq 10$ \\
& $C_{L_{\max } \text { Land: } \leq 6}$ & $C_{L_{\max }}$ Land: $\leq 7$ \\
Electric Motor & No additional power at takeoff & $20 \%$ additional power at takeoff \\
& & Reverse thrust on landing \\
Advanced flight & Current required margins on & Reduced margins on touchdown \\
controls & touchdown speed and runway & speed and runway length \\
& length & \\
\hline
\end{tabular}

\section{Blown Lift Feasibility}

One question that arises when proposing a blown lift vehicle is what the useful limits on the amount of lift generated are - at what point does increasing the power to the blown lift system no longer provide any 
system-level benefit? One limit is the thrust/weight of the vehicle and the weight of the associated power system. If the vehicle has enough power to takeoff vertically, it's not clear there is any benefit to generating additional higher lift coefficients by adding more power.

Another limit is imposed by the landing condition, which has been previously discussed by Patterson[28]. One reasonable assumption that can be made about a STOL UAM aircraft is that it would need to have, while the powered high-lift system is activated, the ability to perform a stabilized approach to landing. Furthermore, that stabilized approach would need to be at some negative flight path angle. If generating a high CL through blowing also generates large amounts of excess thrust such that the vehicle cannot descend, than that high CL is not practical for the landing case. The following section summarizes the approach taken to estimate where this practical limit lies.

The details of the following calculate require some assumptions about high-level vehicle parameters. For the purposes of exploring the design space a generic small aircraft equipped with a blown flap system was modeled, with the key parameters shown in Table 3. This size and configuration may be representative of a UAM STOL aircraft or a modern GA aircraft. It should not be confused with the point of departure vehicles in subsequent sections.

Table 3: Key parameters of a generic small aircraft used for initial design space assessment

\begin{tabular}{lr}
\hline \hline $\mathrm{WMTO}$ & $2350 \mathrm{lbs}$ \\
$\mathrm{W} / \mathrm{S}$ & $16 \mathrm{lb} / \mathrm{ft} 2$ \\
$\mathrm{AR}$ & 6 \\
$D_{\text {Prop }} / \bar{c}$ & .3 \\
\hline \hline
\end{tabular}

An inviscid model of a blown flap, or jet flap, was developed based on the method of Maskell and Spence[21] and Drela [29]. While this inviscid formulation neglects many of the complicated details of jet flap performance and design, it is useful to gain understanding of general trends. The details of the calculations are presented in Appendix A. A high-level summary of the approach and key results is given here.

Figure 3 shows the forces on a blown lift aircraft as it moves through inertial space along some flight path angle $\gamma$ at an airspeed of $V_{\infty}$. The jet is considered to be uniform across the span, and is assumed to be generated by a propulsor that is parallel to the freestream. The jet exits the control volume at some angle far downstream $\alpha_{i_{\infty}}$, which is a function of both the flap deflection angle $\delta_{f}$ and the overall pressure field induced by the wing. The jet is assumed to stay attached to the wing at all times without separating; the initial jet deflection angle at the trailing edge is also $\delta_{f}$. A key point is that $\alpha_{i_{\infty}}$ and $\delta_{f}$ differ due to the turning of the jet induced by the pressure load on it.

The net force of the jet on the aircraft $F_{J}$ is offset from the stream wise direction by $\alpha_{i_{\infty}}$, and can be usefully decomposed into lift and thrust components $L_{J}$ and $T$. The total lift is the component of the jet force normal to the streamline $L_{J}$ plus the lift due to circulation $L_{C}$. This is also strongly modified by the presence of the jet, and increases substantially from the unpowered case.

If $\alpha_{i_{\infty}}$ is small, the propulsor force is largely in the thrust axis and high power will generate some increased lift with large excess thrust. If $\alpha_{i_{\infty}}$ is large, such as in the case with a fully deflected slipsteam aircraft, then high blowing power will generate very little thrust and a large increase in lift. At large flap angles a substantial amount of drag is produced due to the turning of the jet; in the limit where the flap deflection angle is $90^{\circ}$ no thrust will be produced even for high power.

To illustrate this, the lift polar for a blown wing is shown in Figure 4. This shows the relationship between the lifting force coefficient $C_{L}$ and the net streamwise force coefficient $C_{X}=C_{D}-C_{T}$. The effects of changing angle of attack, increased blowing and increased flap deflection are shown on this plot. The angle of attack range shown is between zero and fifteen degrees, for several different combinations of jet deflection and jet sheet strength. This strength is parametrized by the jet momentum coefficient $C_{J}$, which relates the force of the jet to the overall dynamic pressure.

$$
C_{J}=\frac{F_{J}}{1 / 2 \rho V_{\infty}^{2} S}=\frac{\rho_{J} V_{J}^{2} b h_{j}}{1 / 2 \rho V_{\infty}^{2} S}
$$

$h_{j}$ is the thickness of the jet sheet and is assumed to be equal to the propeller diameter $D_{\text {Prop }}$. The unpowered case where $C_{J}=0$ is shown as the dark blue lines. In this case increasing flap deflection only 


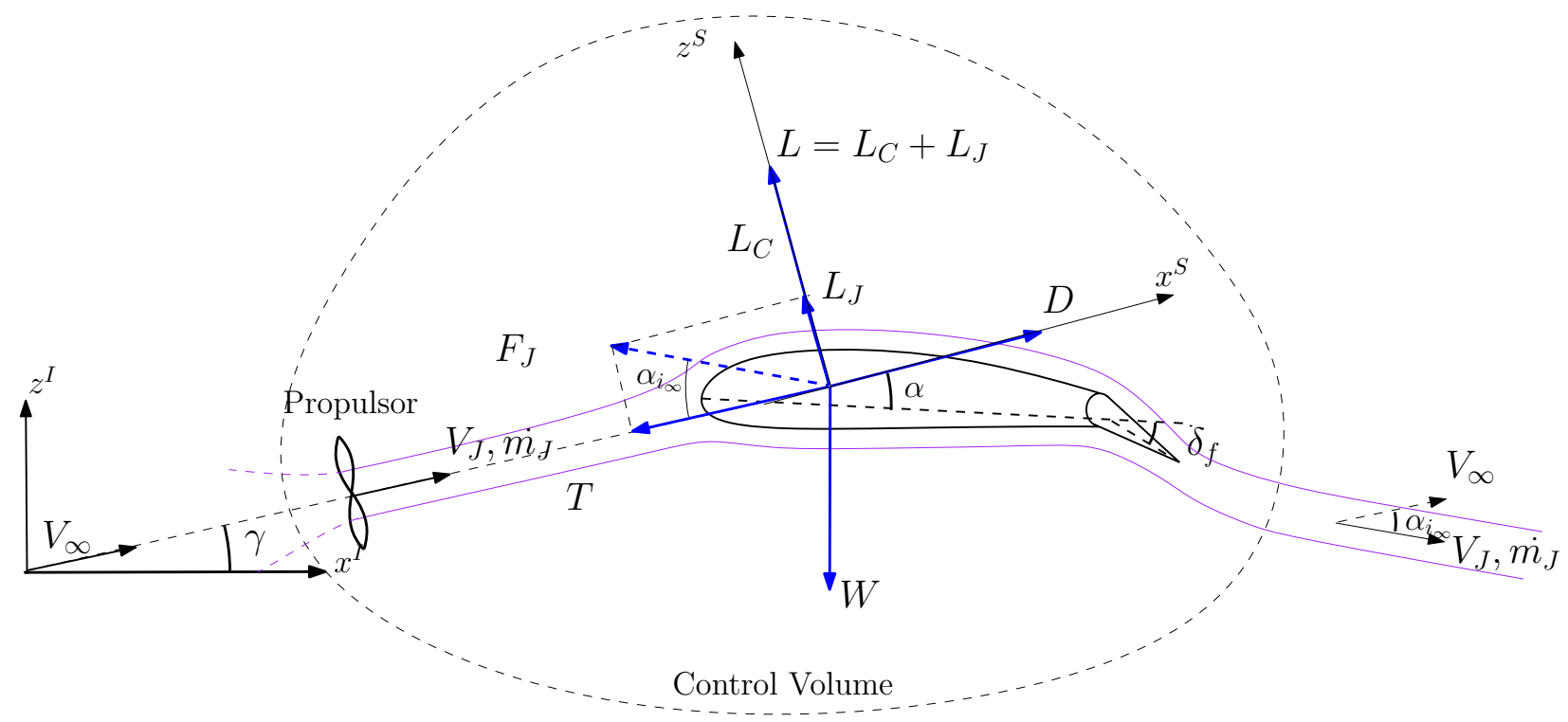

Figure 3: A single-jet conceptual model of the forces on a blown wing, which shows a chordwise cross-section of a wing at some angle of attack $\alpha$ and airspeed $V_{\infty}$ interacting with a uniform jet sheet with velocity $V_{J}$

increases profile drag; the lift increment due to increased flaps was not modeled for the unpowered case as it is a small effect compared to the lift increment due to blown flaps.

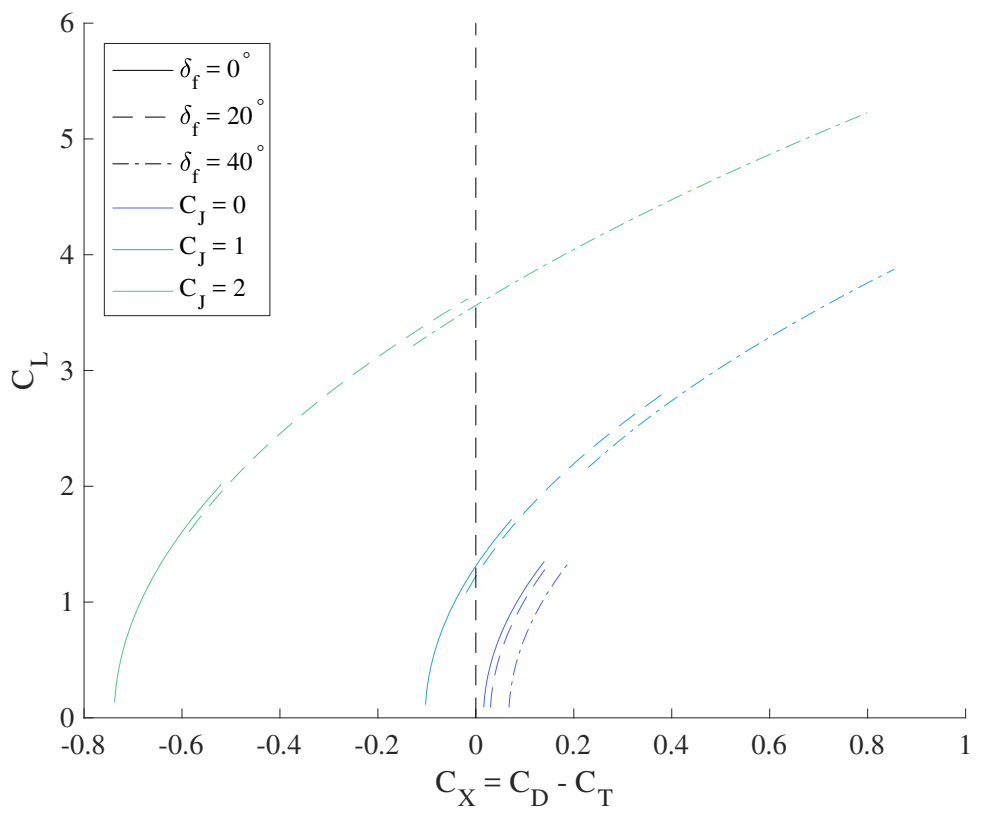

Figure 4: $C_{L}$ is cross-plotted with $C_{X}$ for angles of attack from $0^{\circ}$ to $15^{\circ}$. Increasing the jet strength coefficient $C_{J}$ is shown by changing color, while different flap deflections $\delta_{f}$ are shown by line style. The same angle of attack range is shown for each combination of $\delta_{f}$ and $C_{J}$

For the aircraft to be in steady level flight $C_{X}$ must be zero (thrust and drag must be balanced). This is shown by the solid dashed line in Figure 4. The intersection of each curve with this line can be interpreted 
as showing, for a given jet blowing coefficient $C_{J}$ and flap deflection $\delta_{f}$, the $C_{L}$ where the aircraft is in level flight, assuming no additional thrust or drag is generated. This level flight condition also represents the limit of usable $C_{L}$ on landing; if thrust is greater than drag the vehicle must be climbing or accelerating. Points that lie to the left of the line are not useful for the landing case. This can be seen from the stream wise force balance equation (2); if $C_{X}$ is negative then the flight path angle $\gamma$ must be positive.

$$
\sin \gamma=\frac{-C_{X} \frac{1}{2} \rho V_{\infty}^{2} S}{W}
$$

Speed is determined (for a known $C_{X}, C_{L}, W, S$, and $\rho$ through the associated lifting force balance equation (3). The details of how $C_{L}, C_{X}$, and $C_{J}$ are related are discussed in more detail in Appendix A.

$$
C_{L}=\frac{W \cos \gamma}{\frac{1}{2} \rho V_{\infty}^{2} S}
$$

This polar shows that going to higher blowing coefficients $C_{J}$ substantially increases lift coefficient $C_{L}$, and that large flap deflections are needed to generate the sufficient drag for a stabilized approach to landing. For a given maximum angle of attack $\alpha$, the $C_{J}$ where $C_{X}=0$ and the associated $C_{L}$ can be calculated. This curve is shown as the black line in Figure 5 . It can be seen that very high values of usable $C_{L}$ are achievable as flap deflection starts to increase.

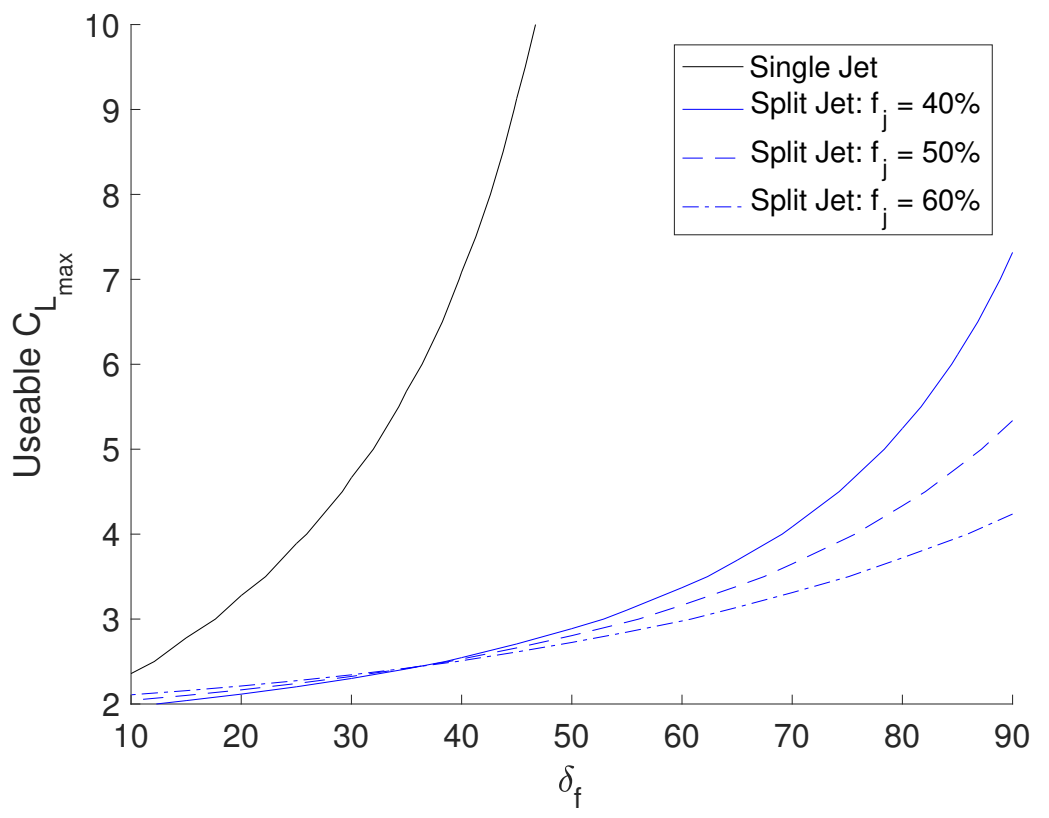

Figure 5: Increasing power and flap deflection with the single jet model can generate very large usable values of $C_{L_{\max }}$, shown by the black line. An alternative split jet model, which is more conservative at higher flap deflections, is shown in blue.

At very large flap deflections some of the assumptions in the original blown wing model may no longer be accurate. Specifically, the small angle approximations and the assumption that the flow will remain attached to the upper surface become questionable. At large flap deflections some separation off the flap upper surface is likely but the details of where and under what conditions it would occur are difficult to predict with handbook methods.

An alternative model shown in Figure 6 is proposed to estimate performance in this high-flap deflection regime. This is similar to the model shown in Figure 3 except that the jet is split by the wing. The bottom portion is deflected by the flap, while the upper portion separates off the upper trailing edge. This model is likely to be pessimistic in terms of performance; in reality, a slotted flap system could keep the upper surface flow attached through large turning angles. The details of the performance of that system are beyond 
the scope of this paper. For an early design space assessment this model provides an estimate of possible performance. The details are again discussed in Appendix A.

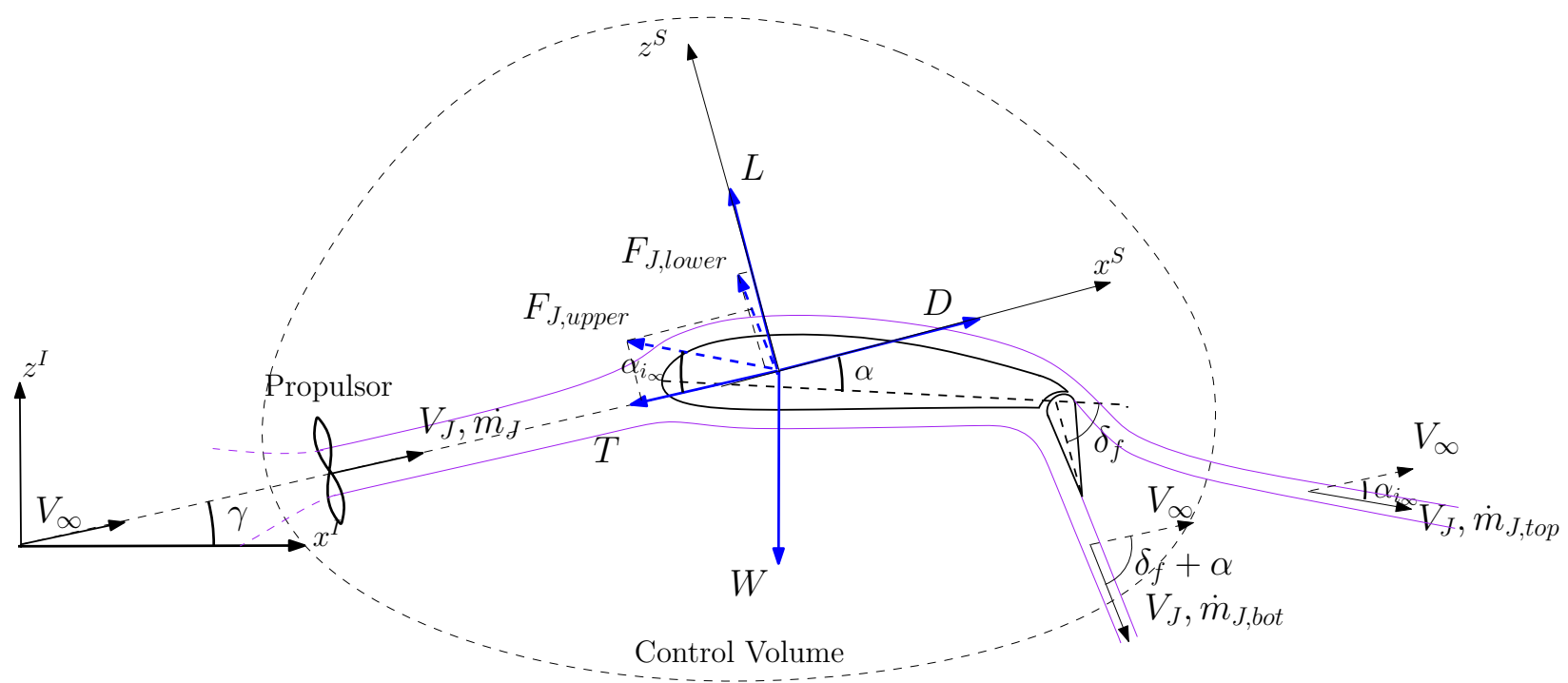

Figure 6: A blown wing is modeled as a single jet fully deflected by the flap (left) and as a jet split by the airfoil(right)

This model introduces another design parameter, which is the ratio of the upper surface jet mass flow to the total mass flow $f_{\text {jet }}=\frac{\dot{m}_{\text {J,top }}}{\dot{m}_{J}}$. $f_{\text {jet }}=1$ corresponds entirely to upper surface blowing while $f_{\text {jet }}=0$ corresponds entirely to a deflected slipstream. The blue lines in Figure 5 show the results of this model for three different values of $f_{\text {jet }}$. The value of this parameter depends on both propeller placement as well as the details of the induced flowfield around the wing; a value of $40 \%$ is used based on the estimated propeller position of the X-57 relative to the wing centerline. This model is not accurate at small flap deflections since it does not account for any turning of the upper surface flow by the flap (which leads to high excess thrust and low useable $C_{L}$ ).

To generate an overview of the design space both models were used, with $50^{\circ}$ selected as the nominal transition point between the two. This overview is shown in Figure 7, on the same axis as Figure 5. The red line corresponds to the solid lines in Figure 5; this is the usable $C_{L}$ limit. Additionally, contours of constant $\gamma$ are shown, as well as contours of constant power.

It can be seen that $C_{L}$ values as high as 7 may be feasible for landing if very high flap deflections are used, with associated high power settings. Even higher $C_{L}$ may be possible if windmilling propellers, spoilers, or other drag generating devices are used, but those are not considered here. At these low airspeed flight conditions the effect of spoilers may be small.

The underlying model used here is a very simplified look at wing blowing. Viscous effects, which will strongly influence the behavior of this entire system, are not captured, nor are effects associated with the swirl and non-uniformity of an actual propeller wake. More work is needed to fully explore the details of generating blown lift via leading edge blowing. For this paper, the current model provides useful intuition about the problem and reasonable first-order estimate of the overall effects of blown lift.

For the design study discussed in the subsequent section, conservative and aggressive limiting values of $C_{L_{\max }}$ for both takeoff and landing were identified. For the conservative case, a $C_{L_{\max }}$ of no greater than 6 was used for both takeoff and landing. For the aggressive case, a $C_{L_{\max }}$ of no greater than 10 was used for takeoff and no more than 7 was used for landing. This reflects the fact that very high $C_{L} \mathrm{~s}$ at landing start to be constrained by excess power and the need to descend.

Additionally, the relationship between power (expressed as a dimensionless energy coefficient $C_{E}$, defined in (33) and $C_{L_{\max }}$ was estimated from this plot, for a representative takeoff $\left(30^{\circ}\right)$ and landing $\left(80^{\circ}\right)$ flap deflections. The forms of the fit are compatible with the formulation of the design problem as discussed below, and based on the method of Hoburg and Kirschen [30]. 


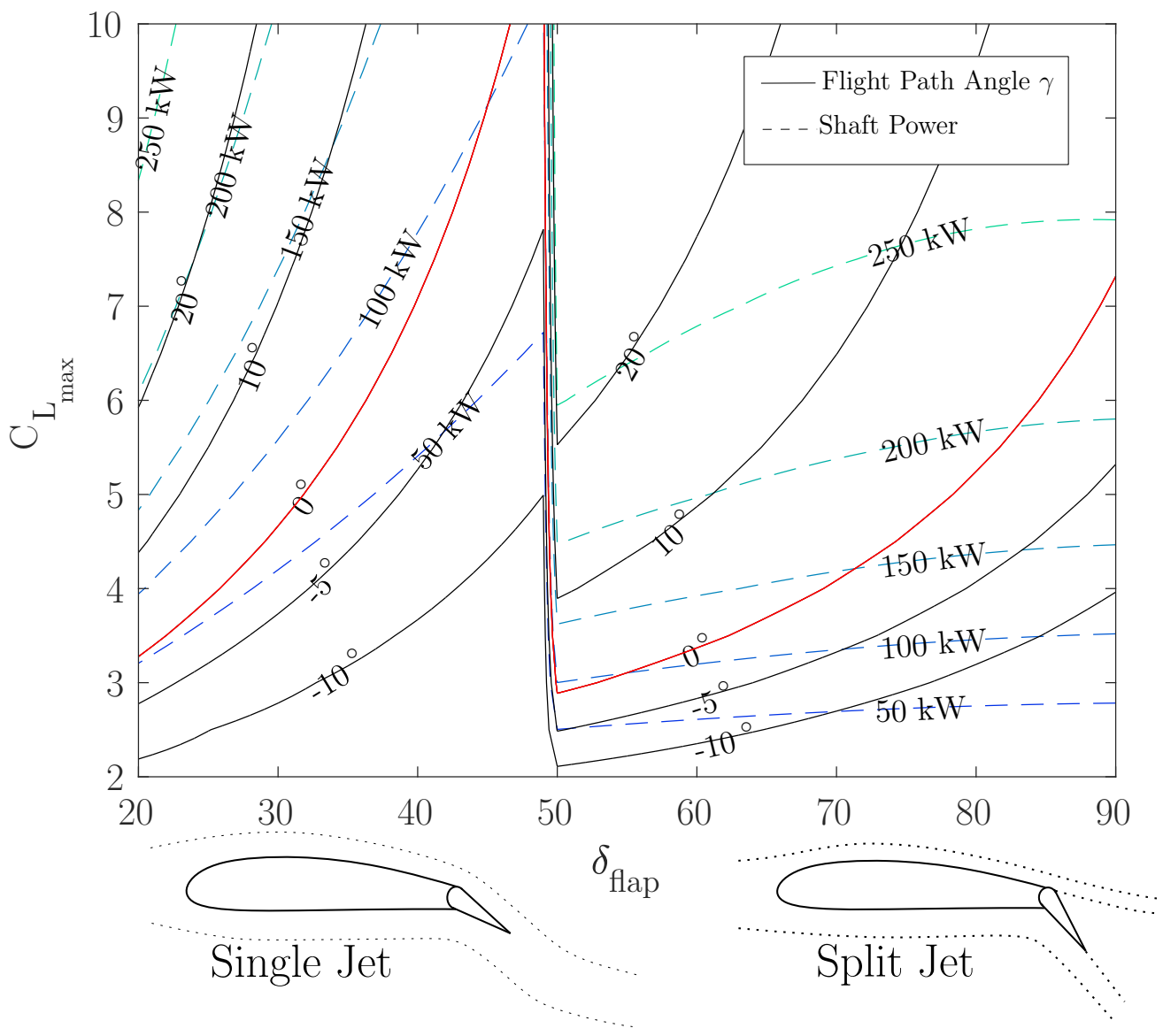

Figure 7: This plot of $C_{L_{\max }}$ vs flap deflection shows that very high lift may be practical during approach and landing if large flap deflections are used.

$$
\begin{aligned}
& C_{E}^{0.1} \geq 0.623 C_{L_{\max }}^{0.342} \\
& C_{E}^{0.1} \geq 0.780 C_{L_{\max }}^{0.251}
\end{aligned}
$$

These were used in the vehicle feasibility study discussed in Section V for the takeoff (4) and landing (5) conditions.

\section{Vehicle Feasibility}

A sizing study using geometric programming (GP) optimization was performed to understand how short takeoff and landing requirements affect vehicle performance and design. This section describes the assumptions and equations used in the optimization model for vehicle size, cruise performance, and takeoff and landing distances.

Geometric programming was selected as a means of evaluating this trade space because of its speed and reliability. Geometric programming is a special type of convex, non-linear optimization[31]. Because it is convex, even GPs with thousands of variables can be solved quickly[31]. Additionally, recent research has shown that GPs can be used to effectively evaulate aircraft design trade spaces[32][33].

\section{A. Vehicle Assumptions}

To model the vehicle as a GP, equations capturing the assumptions discussed in this section are expressed in a GP form and included in the optimization model. A comprehensive list of equations used to model the 
aircraft can be found in Appendix B.

The vehicle configuration is assumed to have a fully electric architecture. To achieve the high lift coefficients the wing is blown using multiple rotors placed across the span of the wing. The vehicle empennage is conventional with a single horizontal and vertical tail.

A high level weight breakdown includes battery, passenger, wing, motor and structural weights. The structural weight includes the weight of the fuselage structure and empennage and is assumed to be $20 \%$ of the gross take off weight. Passenger weight estimates are based on FAA guidance [34]. The battery weight is determined by the required range the aircraft and has an assumed specific energy value. The motor weight is calculated using a specific power ratio based on the maximum power used by the aircraft.

The conceptual structure of the wing is a cap spar with unidirectional carbon fiber on the top and bottom surfaces of the wing wrapped in a shear web. The spar, which is assumed to take all of the bending loads, is sized to withstand a $4 \mathrm{~g}$ load with a $50 \%$ safety margin. The overall weight of the wing is a summation of the spar and wing skin. A $40 \%$ weight margin is added on the wing to account for control surfaces, motor mounts and additional wing structure.

During steady level flight the aircraft drag is calculated as the induced drag of the wing with an assumed span efficiency, the profile drag of a representative airfoil, and parasite drag that scales with the area of the wing. A constant propeller efficiency is used to calculate the required shaft power during cruise.

\section{B. Takeoff and Landing Models}

The takeoff model was adapted from Raymer's takeoff equations to fit a GP compatible form[35]. Using equations of motion the takeoff state can be expressed

$$
T-D-\mu\left(W_{\mathrm{MTO}}-L\right)=\frac{W_{\mathrm{MTO}}}{g} \frac{d V}{d t} .
$$

This can be simplified to

$$
\begin{aligned}
& \frac{d V}{d t}=g\left(\frac{T}{W_{\mathrm{MTO}}}-\mu\right)-\frac{g}{W_{\mathrm{MTO}}}\left(\frac{1}{2} \rho S V^{2}\left(C_{D_{g}}-\mu C_{L_{g}}\right)\right) \\
& \frac{d t}{d V}=\frac{1}{A-B V^{2}}
\end{aligned}
$$

The takeoff ground run distance can then be expressed by taking the integral of Equation 8 to achieve

$$
S_{\mathrm{TO}}=\frac{1}{2 B} \ln \frac{A}{A-B V^{2}}
$$

The natural log function can be approximated to make Equation 9 GP-compatible by

$$
\ln \frac{A}{A-B V^{2}} \approx 5.6 \times 10^{-4} A^{-6.04}\left(B V^{2}\right)^{6.04}+1.0 A^{-0.001}\left(B V^{2}\right)^{0.001}+7.5 \times 10^{-4} A^{-1.276}\left(B V^{2}\right)^{1.275}
$$

with an average $\log$ error of $0.06 \%$. The terms $A$, and $B$, are constrained by

$$
\begin{aligned}
\frac{T}{W_{\mathrm{MTO}}} & \geq \frac{A}{g}+\mu \\
B & \geq \frac{g}{W_{\mathrm{MTO}}} \frac{1}{2} \rho S C_{D_{g}}
\end{aligned}
$$

where the $\mu C_{L_{g}}$ term is neglected as a conservative approximation for $B$ to preserve GP-compatibility. The landing ground roll distance is calculated using conservation of energy,

$$
S_{\text {land }} \geq \frac{1}{2} \frac{V^{2}}{N g}
$$

where $N$ is the deceleration factor ( $N=1$ corresponds to a 1 -g deceleration). The velocity $V$, is calculated using a $30 \%$ margin on the stall speed 


$$
V=1.3 V_{\text {stall }}=\sqrt{\frac{2 W_{\mathrm{MTO}}}{\rho S C_{L_{\mathrm{TO}}}}} .
$$

$C_{L_{\mathrm{TO}}}$ is the value of $C_{L_{\max }}$ at takeoff used to compute the stall speed. This is considered a free variable related to the jet kinetic energy coefficient $C_{E}$ by (4). This couples propulsion system power and hence weight to the effectiveness the blown lift system by (15). $C_{L_{\max }}$ is not permitted to become arbitrarily large but is subject to the feasibility limits discussed in Section IV and summarized in Table 2. The limits on maximum lift coefficient are different for landing and takeoff but the method of calculating power is the same.

$$
P_{\text {shaft }} \eta_{p} \geq \frac{1}{2} \rho V_{\infty}^{3} S\left(C_{E}\right)
$$

The deceleration factor is a function of the technologies used to stop the aircraft and include, but are not limited to: brakes, reverse thrust from electric motors, and drag. This was used instead of a more conventional braking model because, as discussed subsequently, these vehicles are driven primarily by landing constraints. This creates an incentive to use some type of thrust reversal or dedicated braking thrust system to shorten the landing distance. The details of this system are an important vehicle level design trade; the landing deceleration used in this system-level study becomes the design requirement for a future vehicle design effort. Passenger comfort and system weight are additional considerations. To understand how the g-loading constant varies with different amounts of reverse thrust, the ground roll and deceleration factor are calculated using the generic UAM aircraft as an example case. Table 4 shows the deceleration factor for different amounts of reverse thrust.

Table 4: Landing Case for the Generic Aircraft

\begin{tabular}{lcc}
\hline \hline & $\begin{array}{c}\text { Ground } \\
\text { Roll Distance }\end{array}$ & $\begin{array}{c}\text { Deceleration } \\
\text { Factor }(N)\end{array}$ \\
\hline Brakes only (dry) & $925[\mathrm{ft}]$ & 0.37 \\
Brakes $+10 \%$ reverse thrust & $850[\mathrm{ft}]$ & 0.4 \\
Brakes $+50 \%$ reverse thrust & $625[\mathrm{ft}]$ & 0.55 \\
Brakes $+100 \%$ reverse thrust & $425[\mathrm{ft}]$ & 0.73 \\
\hline
\end{tabular}

For both the landing and takeoff constraints it is assumed that the velocity has a $30 \%$ margin above the stall velocity[36]. For the purposes of this study, deceleration corresponding to braking with a small amount of reverse thrust $(.4 \mathrm{~g})$ was used for the conservative case, while a more powerful thrust reversal system $(.7 \mathrm{~g})$ was used for the aggressive case.

A $40 \%$ margin is placed on the ground roll distance to determine runway length[37]. For this vehicle, balanced field length considerations were not considered as the loss of a single engine is only a small reduction in total thrust. Because the majority of sites being considered are elevated, takeoff or landing distance over a $35 \mathrm{ft}$ obstacle was not included in the model. It will be evaluated on a case by case basis for different runway locations.

$$
\begin{aligned}
S_{\text {runway }} \geq 1.4 S_{\mathrm{TO}} \\
S_{\text {runway }} \geq 1.4 S_{\text {land }}
\end{aligned}
$$

\section{Vehicle Trade Studies}

Using the geometric programming model of a STOL aircraft perviously described, tradeoffs between runway length and vehicle performance were evaluated. The model consists of 105 free variables and can be solved in approximately 0.1 seconds. Because aircraft cost scales with aircraft weight as a first order approximation, the objective function throughout is to minimize weight, $\min \left(W_{\mathrm{MTO}}\right)$. Key parameter values are defined in Table 5 . 
Table 5: Baseline Design Parameters

\begin{tabular}{lc}
\hline \hline Parameter & Value \\
\hline$\eta_{\text {elec }}$ & 0.9 \\
$h_{\text {batt }}$ & $150[\mathrm{Whr} / \mathrm{kg}]$ \\
$(P / W)_{\text {motor }}$ & $7.0[\mathrm{~kW} / \mathrm{kg}]$ \\
$R$ & $100[\mathrm{nmi}]$ \\
$V_{\min }$ & $100[\mathrm{kts}]$ \\
$C_{L_{\max }}($ Landing $)$ & $\leq 6.0$ \\
$C_{L_{\max }}(\mathrm{TO})$ & $\leq 6.0$ \\
$N$ & $0.4 \mathrm{~g}$ \\
$\eta_{\text {prop }}$ & 0.8 \\
\hline
\end{tabular}

To understand how passenger and runway requirements affect vehicle weight, the GP model was solved 30 times in 3.46 seconds. The results are shown in Figure 8(a), each point on the graph corresponding to a unique optimization solution for vehicle size. From this study it is observed that runway lengths shorter than $150 \mathrm{ft}$ are practically infeasible for this set of parameters. It is also observed that the runway length is fairly insensitive to number of passengers.

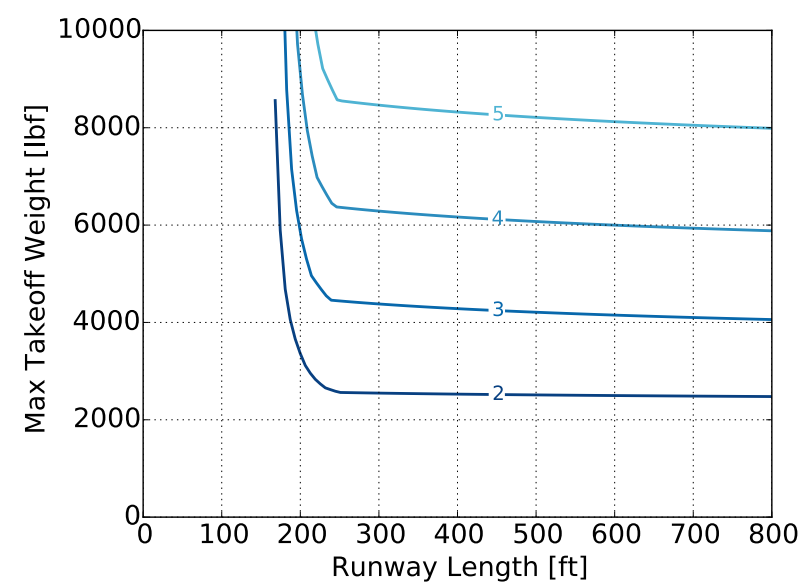

(a) Contours of number of passengers

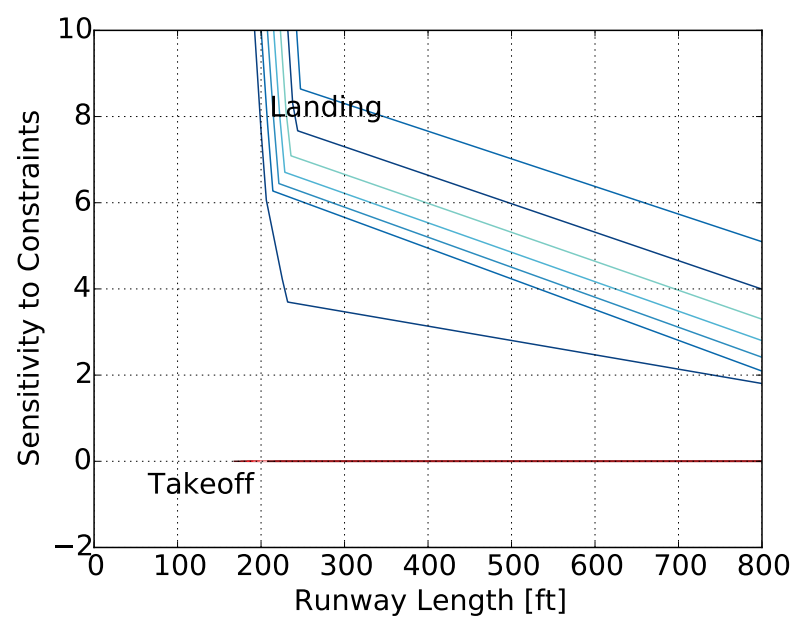

(b) Sensitivity to landing and takeoff constraints

Figure 8: Trade space of aircraft weight, number of passengers and runway length.

To effectively shorten the field length it is important to know whether the vehicle size is driven by the landing or takeoff constraints. Qualitatively, the landing model has a direct effect on wing loading as shown in Equations 13 and 14. The takeoff model primarily effects the thrust to weight ratio but also has a small effect on the wing loading (Equation 9$)$. The effect of the thrust to weight ratio $(T / W)$ and the wing loading $(W / S)$ is shown in figure 9 . The thrust to weight ratio drives the motor weight. The wing loading drives the wing size, which in turn drives the wing weight, drag and ultimately battery weight. This argument implies that the landing model would constrain the vehicle size.

The hypothesis that vehicle size is more constrained by landing is confirmed by looking at the sensitivity to both the landing and takeoff models. The sensitivity to a variable in a geometric program is defined as the percentage change in the objective function for a $1 \%$ change in that variable's value. Therefore, if the sensitivity to the landing constraints is greater in magnitude than the sensitivity to the take off constraints, the system is landing constrained. Figure $8(\mathrm{~b})$ shows this is the case for these aircraft. The sensitivity to the takeoff constraints is not zero because the takeoff model requires a thrust to weight ratio which determines the motor weight. 


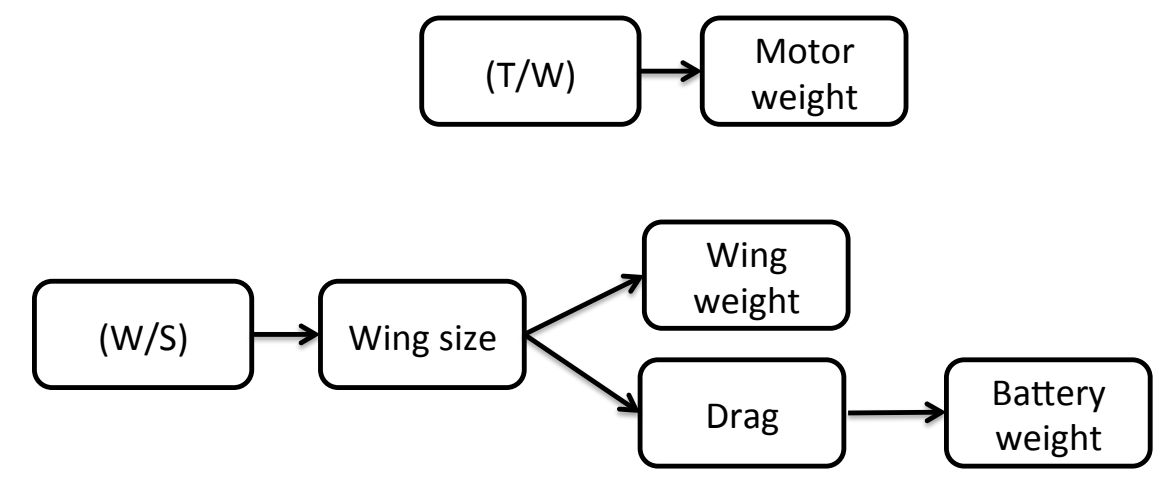

Figure 9: Effect of thrust to weight $(\mathrm{T} / \mathrm{W})$ and wing loading $(\mathrm{W} / \mathrm{S})$ ratios on vehicle size.

\section{Requirement Trade Studies}

Because of the low wing loading required in the takeoff and landing models, the optimum cruise speed of STOL vehicles are fairly slow. Therefore, a minimum cruise speed requirement is imposed in the model,

$$
V_{\text {cruise }} \geq V_{\text {min }} \text {. }
$$

The minimum speed requirement affects the cruise power requirement and consequently the amount of batteries needed. One way to achieve higher range or shorter runways is to decrease the required minimum speed during cruise. Conversely, flying faster requires shorter ranges or longer runways. This trade off is shown in Figure 10. The flat portion of the curves indicates that the aircraft is not constrained by the minimum cruise speed (i.e. that constraint is not active) because the optimum cruise speed for that set of requirements is faster than the minimum cruise speed.

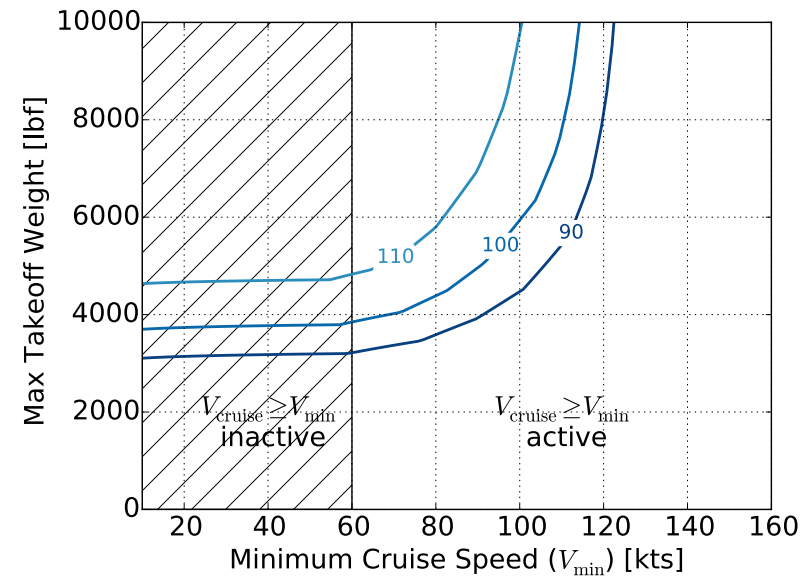

(a) Contours of range[nmi]

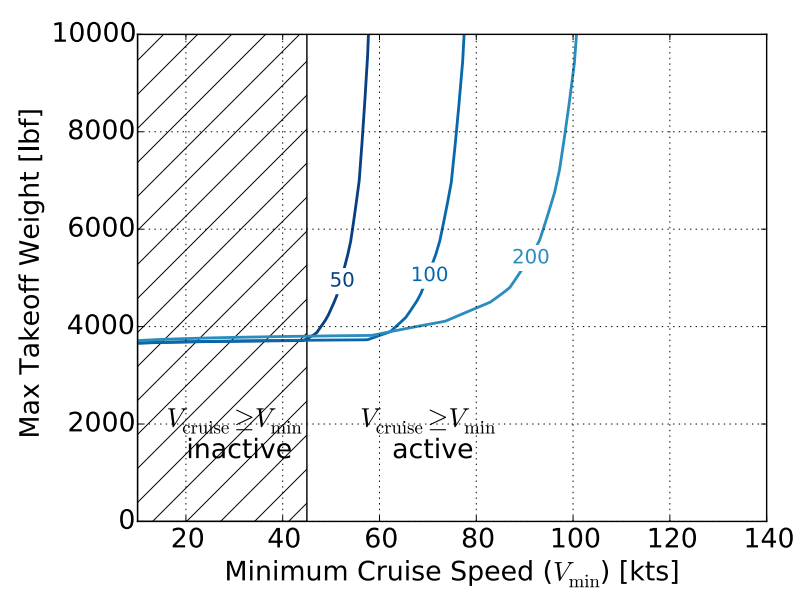

(b) Contours of runway length[ft]

Figure 10: Trade study between requirements of runway length, minimum speed and range.

\section{E. Advanced Technology Trade Studies}

The previous section showed fundamental trade studies and trends for how runway length varies with performance. It is also possible to shorten runway length through advanced technology. As discussed previously, a number of technologies could help reduce the required runway length including power bursts from electric motors, reverse thrust on landing, advanced flight controls, and improved battery technology. The effect of these technology advances on required runway length can be observed by changing a few 
parameters from the baseline conservative case and re-solving the optimization model. Table 6 compares the conservative parameters to the aggressive technology parameters that were assumed in the optimization model based off of the technologies discussed in Table 2.

Table 6: Advanced Technology Parameter Assumptions

\begin{tabular}{llcc}
\hline \hline Technology & Parameter & Conservative Value & Aggressive Value \\
\hline Battery improvements & $h_{\text {batt }}$ & $150[\mathrm{Whr} / \mathrm{kg}]$ & $300[\mathrm{Whr} / \mathrm{kg}]$ \\
Motor power burst & $(P / W)_{\text {motor }}$ & $7.0[\mathrm{~kW} / \mathrm{kg}]$ & $8.4[\mathrm{~kW} / \mathrm{kg}]$ \\
Blown wing & $C_{L_{\max }}$ (Landing) & $\leq 6.0$ & $\leq 7.0$ \\
Blown wing & $C_{L_{\max }}$ (TO) & $\leq 6.0$ & $\leq 10.0$ \\
Reverse thrust & Deceleration Factor & 0.4 & 0.7 \\
Advanced flight controls & Runway margin & $40 \%$ & $20 \%$ \\
Advanced flight controls & Stall speed margin & $30 \%$ & $10 \%$ \\
\hline
\end{tabular}

Understanding the extremes between the conservative case and a more aggressive case is useful in determining a feasible vehicle design and vehicle requirements. Figure 11 shows the same trade study as figure 8 , but with the updated parameter values shown in Table 6.

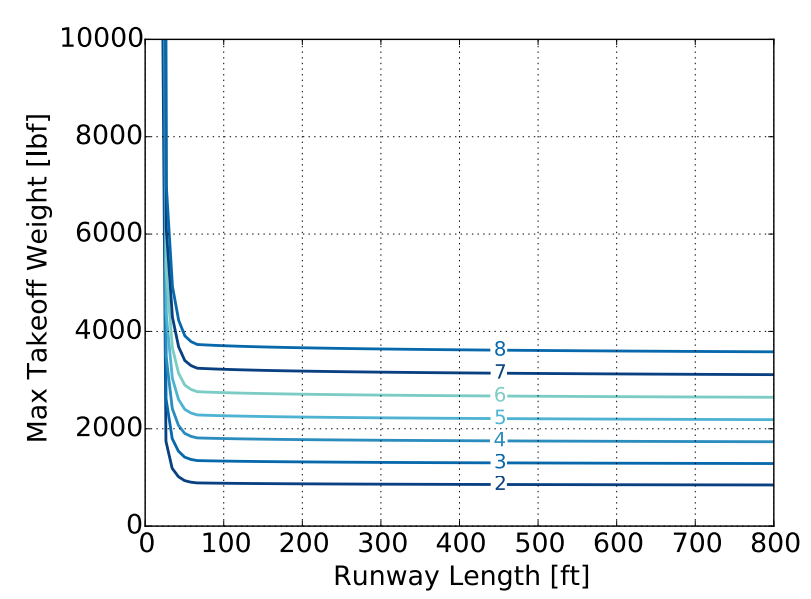

(a) Contours of number of passengers

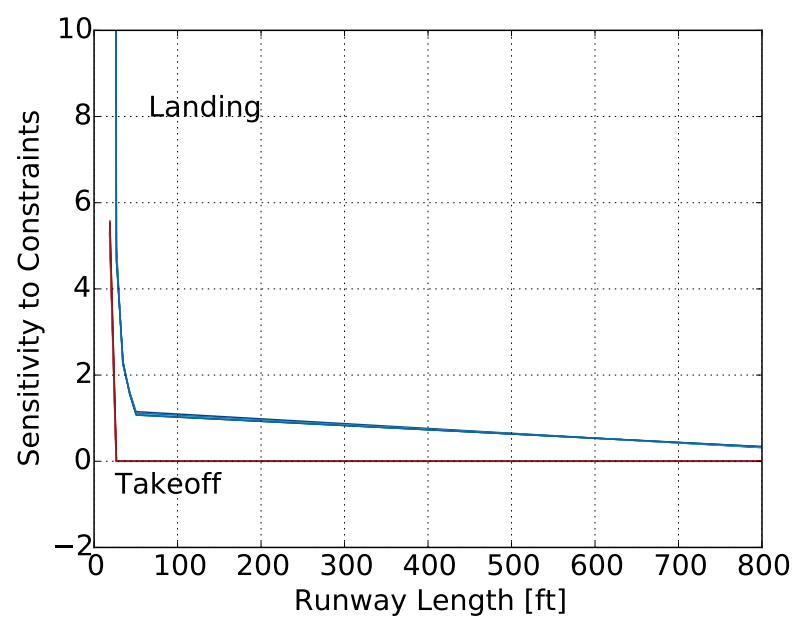

(b) Sensitivity to landing constraints

Figure 11: Trade space of aircraft weight, number of passengers and runway length for advanced technology assumptions.

As observed in figure 11(a), the advanced technology assumptions allow for a much shorter runway than the baseline case showing that runways below even $100 \mathrm{ft}$ might be possible. To understand which parameters have the largest effect on this trade study, each parameter can be varied one at a time from the baseline case. Figure 12 show variations on the 4 passenger contour from figure $8(\mathrm{a})$.

Note that increasing the maximum lift coefficient or the deceleration factor has no effect for higher runway lengths. This is because at higher runway lengths the size of the aircraft is constrained by the range requirement but not the runway requirement. Increasing the battery specific energy however, is always beneficial because that lowers the battery weight which improves the whole system.

\section{F. Point of Departure Vehicle}

A point of departure vehicle was sized for both the conservative case and aggressive case, whose parameter values are listed in Table 6 . Key variable values for both solutions are listed in Table 7. 


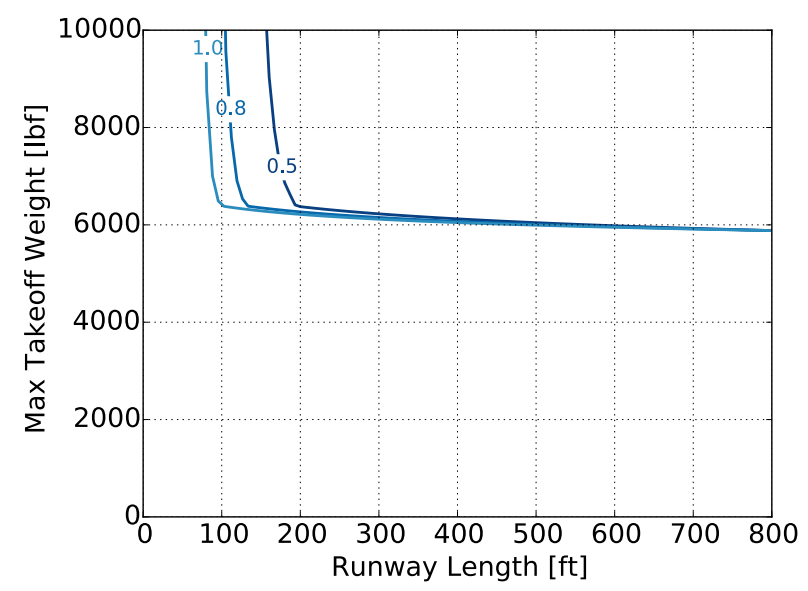

(a) Contours of deceleration factor

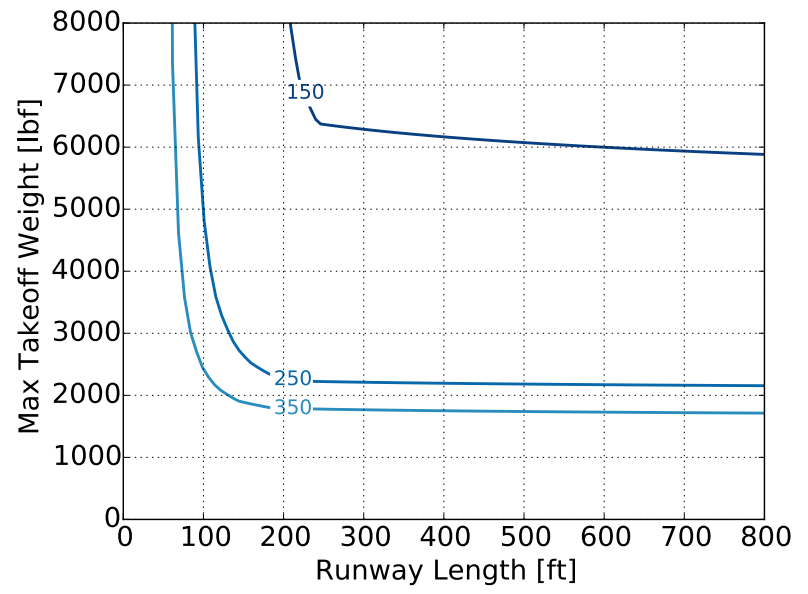

(b) Contours of battery specific energy

Figure 12: Trade space of aircraft weight, number of passengers and runway length for advanced technology assumptions.

Table 7: Design Variables

\begin{tabular}{lcc}
\hline \hline Parameter & Conservative Case & Aggressive Case \\
\hline$W_{\text {MTO }}$ & $5880[\mathrm{lbf}]$ & $1730[\mathrm{lbf}]$ \\
$W_{\text {batt }}$ & $2960[\mathrm{lbf}]$ & $450[\mathrm{lbf}]$ \\
$N_{\text {pax }}$ & 4 & 4 \\
$A R$ & 8.0 & 7.8 \\
$b$ & $47[\mathrm{ft}]$ & $25[\mathrm{ft}]$ \\
$(W / S)$ & $21\left[\mathrm{lbf} / \mathrm{ft}^{2}\right]$ & $21\left[\mathrm{lbf} / \mathrm{ft}^{2}\right]$ \\
$\left.S_{\text {runway }}\right]$ & $300[\mathrm{ft}]$ & $100[\mathrm{ft}]$ \\
\hline
\end{tabular}

One significant advantage this aircraft offers over an electric VTOL vehicle is the capacity to carry more passengers. The proposed vehicle can carry 4 persons, while electric VTOL vehicles are typically limited to 2. It is also noted that the runway length for the conservative case is $300 \mathrm{ft}$ but runway lengths of less than $100 \mathrm{ft}$ may be possible if all of the advanced technology is used. Depending on the extent to which those advanced technology levels can be reached, 100-300 ft runways are possible if infrastructure availability requires it. This is especially true if the speed or payload requirements are slightly reduced. This information can be used to inform infrastructure decisions.

Figure 13 shows a visualization of the point of departure vehicle based on the conservative technology estimates. The high wing configuration improves passenger access, reduces ground effect on landing, and allows easy maintenance access to batteries. A key feature of this point of departure design is that there will be sufficient space in the wing to store all the batteries. This physical separation from the passengers and other battery packs helps manage the risk associated with thermal runaway, as it reduces the need for a firewall. The wing primary structure could also become dual-purpose, carrying aerodynamic loads as well as physically isolating the battery packs. This would minimize the weight penalty for battery containment.

\section{Conclusion}

This analysis has showed that eSTOL aircraft are a feasible option for a UAM network with significant advantages relative to vehicle payload and certification risk. Vehicle runway lengths as short as 100-300 ft are shown to be feasible with current or near-future technology, although a cruise speed reduction or better battery specific energy may be required to achieve $100 \mathrm{ft}$. Runway lengths of $300 \mathrm{ft}$ are readily achievable 


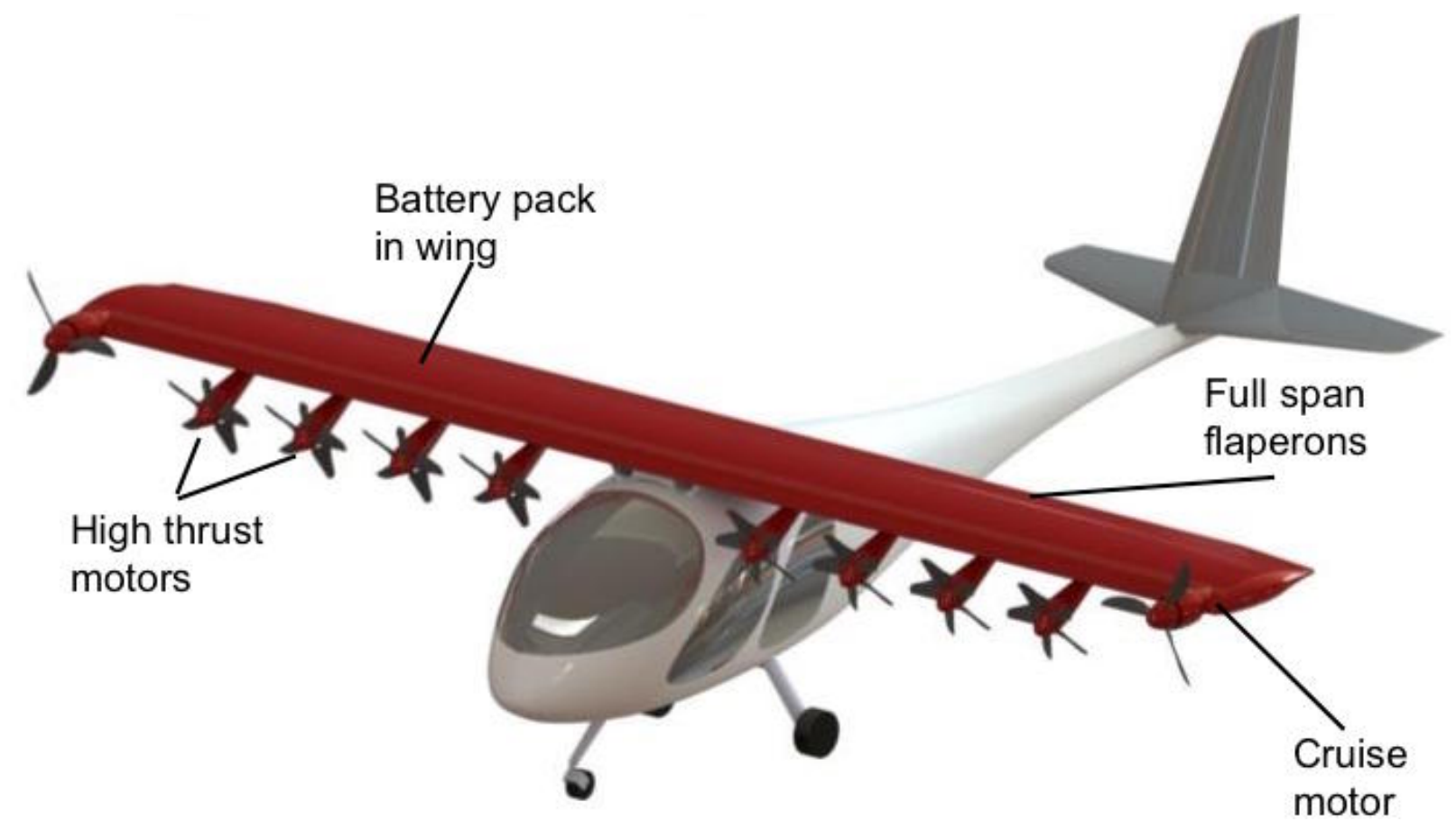

Figure 13: Overview of 4-seat point of departure vehicle

for eSTOL aircraft with current technology, which is also achievable from the perspective of building infrastructure within urban centers. STOL aircraft offer a near-term pathway to implementing a UAM network, allowing a company to capture early market share and start developing the operational knowledge of how to conduct these types of operations in the existing ATC environment.

Additional work is required to more fully develop the eSTOL concept, especially in regards to the effectiveness and required power of the blown lift system, required battery safety systems and the associated weight penalties, flight procedures and control authority at low airspeeds, and engine-out characteristics. Based on this initial assessment, STOL is a feasible option for moving people in and out of dense urban and areas and potentially offers a lower-risk pathway towards the development of useful UAM systems.

\section{A. Blown Lift Modeling}

This appendix details the equations used for modeling the performance of a blown wing aircraft. Two models are developed to examine a blown wing aircraft - a single jet model for small flap deflections and a split jet model for larger flap deflections. Both models are based on the inviscid formulation of Maskell and Spence [21] and Drela [29], with a viscous drag correction based on wetted area and the exposed area of the deflected flaps.

\section{Single Jet}

Figure 3 shows the overview of the single jet model based on [21] and [29]. In this model, the flow is assumed to be inviscid, and the height of the jet sheet is considered to be small relative to the curvature at any point on the airfoil. The jet sheet is thus assumed to remain attached to the airfoil until the flap trailing edge. It is further assumed that the jet sheet is deflected to the flap deflection angle $\delta_{f}$ at the airfoil trailing edge, and exits the control volume at some far downstream induced angle $\alpha_{i_{\infty}}$.

Forces on the airfoil are decomposed parallel and normal to the incoming streamline. In general terms, the lift of the airfoil is the sum of the circulation induced-lift $L_{C}$ and the lift from the jet $L_{T}$, which is the vertical component of the jet momentum as it leaves at some angle $\alpha_{i_{\infty}}$. If the jet is assumed to be uniform across the wing,

$$
L=L_{C}+L_{T}
$$




$$
\begin{gathered}
L_{C}=\frac{1}{2} \rho V_{\infty}^{2} \int c_{l} c d y \\
L_{T}=\int d \dot{m}_{j} V_{j} \sin \alpha_{i_{\infty}} \approx b \rho h_{j} V_{j}^{2} \sin \alpha_{i_{\infty}}
\end{gathered}
$$

The net streamwise force $F_{X}=D-T$ is the difference between thrust and drag. In this convention $F_{X}$ is positive when drag is greater than thrust. The total drag $D$ is decomposed into drag induced by the circulation $D_{C}$, the viscous profile drag $D_{P}$, and the drag induced by the turning of the jet $D_{T}$.

$$
\begin{gathered}
F_{X}=D_{C}+D_{P}-\left(T-D_{T}\right) \\
D_{C}=\frac{1}{2} \rho V_{\infty}^{2} \int c c_{l} \alpha_{i} d y \\
D_{T}=\int d \dot{m}_{j} V_{j}\left(1-\cos \alpha_{i_{\infty}}\right) \\
D_{P}=\frac{1}{2} \rho V_{\infty}^{2} \int c c_{d} d y
\end{gathered}
$$

The streamwise component of the force from the jet (thrust) can be defined as a spanwise integral.

$$
T=\int d \dot{m}_{j}\left(V_{j}-V_{\infty}\right)
$$

It is useful to consider the net propulsive force $T-D_{T}$

$$
T-D_{T}=\int d \dot{m}_{j}\left(V_{j} \cos \alpha_{i_{\infty}}-V_{\infty}\right)=b \rho h_{j} V_{j}\left(V_{j} \cos \alpha_{i_{\infty}}-V_{\infty}\right)
$$

for a uniform jet sheet.

It is also useful to define the following dimensionless jet coefficients for a $2 \mathrm{D}$ jet.

$$
\begin{gathered}
c_{Q} \equiv \frac{\dot{m}^{\prime}}{\rho_{\infty} V_{\infty} c} ; \dot{m}^{\prime} \approx \rho_{j} V_{j} h_{j} \\
c_{J} \equiv \frac{J^{\prime}}{\frac{1}{2} \rho_{\infty} V_{\infty}^{2} c} ; J^{\prime} \approx \rho_{j} V_{j}^{2} h_{j} \\
c_{E} \equiv \frac{E^{\prime}}{\frac{1}{2} \rho_{\infty} V_{\infty}^{3} c} ; E^{\prime} \approx \frac{1}{2} \rho_{j} V_{j}^{3} h_{j}
\end{gathered}
$$

The 3D equivalents are given as

$$
\begin{aligned}
C_{Q} & \equiv \frac{1}{S} \int c_{Q} c d y=\frac{V_{j}}{V_{\infty}} \frac{h_{j}}{c} \\
C_{J} & \equiv \frac{1}{S} \int c_{J} c d y=2 \frac{V_{j}^{2}}{V_{\infty}^{2}} \frac{h_{j}}{c} \\
C_{E} & \equiv \frac{1}{S} \int c_{E} c d y=\frac{V_{j}^{3}}{V_{\infty}^{3}} \frac{h_{j}}{c}
\end{aligned}
$$

assuming low-speed flow.

Using these, (22) can be non-dimensionalized.

$$
C_{X}=C_{D_{P}}+C_{D_{C}}-C_{J} \cos \alpha_{i_{\infty}}+2 C_{Q}
$$

The normal force can likewise be expressed as

$$
C_{L}=C_{L_{C}}+C_{J} \sin \alpha_{i_{\infty}}
$$

In the case of a blown wing $C_{L_{C}}$ is strongly influenced by $V_{J}$ ( parameterized by $C_{J}$ ). Similarly, $\alpha_{i_{\infty}}$ is affected both by $C_{J}$ and the jet/flap deflection angle $\delta_{f}$. 
When the wing is at small $\alpha$, the variations of $C_{L_{C}}$ with $C_{J}$ as well as the effect of jet deflection on $\alpha_{i_{\infty}}$ can be estimated based on [21]. The $2 \mathrm{D}$ lift coefficient $C_{L}^{(2)}$ is given by (36).

$$
C_{L}^{(2)}=(1+t / c)\left(\delta_{f} \frac{\partial C_{L}}{\partial \delta_{f}}+\alpha \frac{\partial C_{L}}{\partial \alpha}\right)-t / c\left(\delta_{f}+\alpha\right) C_{J}
$$

The derivatives of $C_{L}$ with respect to $\alpha$ and $\delta_{f}$ are given as a function of $C_{J}$ by (37) and (38)

$$
\begin{gathered}
\frac{\partial C_{L}}{\partial \delta_{f}}=2 \sqrt{\pi C_{J}} \sqrt{1+0.151 \sqrt{C_{J}}+0.139 C_{J}} \\
\frac{\partial C_{L}}{\partial \alpha}=2 \pi\left(1+0.151 \sqrt{C_{J}}+0.219 C_{J}\right)
\end{gathered}
$$

This total lift coefficient due to circulation $C_{L_{C}}$ for a $3 \mathrm{D}$ wing can be related to $C_{L}^{(2)}$ via (39). The additional terms in this equation are a correction for the induced downwash from a finite-span wing assuming the lift distribution is elliptical across the span. A complete derivation is provided in [21].

$$
C_{L_{C}}=C_{L}^{(2)}-\alpha_{i} \frac{\partial C_{L}}{\partial \alpha}-\left(\alpha_{i_{\infty}}-\alpha_{i}\right)\left(\frac{\partial C_{L}}{\partial \alpha}-2 \pi\right)
$$

where

$$
\begin{gathered}
\alpha_{i_{\infty}}=(2 / \pi) \frac{C_{L}^{(2)}}{A R+\left(\frac{2}{\pi}\right) \frac{\partial C_{L}}{\partial \alpha}-2} \\
\alpha_{i}=\frac{1}{2} \alpha_{i_{\infty}}(1-\sigma) \\
\lambda \equiv \frac{\alpha_{i_{\infty}}}{\delta_{f}+\alpha} \\
\sigma \equiv \frac{(1-\lambda) \frac{C_{J}}{\pi A R}}{\lambda-(1-\lambda) \frac{C_{J}}{\pi A R}}
\end{gathered}
$$

To determine the $C_{J}$ required to achieve some desired total $C_{L_{\text {spec }}}$, Eqns. 36 - 43 can be solved using a Newton method to drive the residual $\mathcal{R}=C_{L}-C_{L_{\mathrm{spec}}}$ to zero, for a given $A R, \alpha$, and $\delta_{f} . \alpha_{i_{\infty}}$ and $\alpha_{i}$ are also used in Eqn. 34 to compute the net streamwise forces on the airfoil.

The drag coefficient due to circulation is a function of the induced downwash angle $\alpha_{i_{\infty}}$.

$$
C_{D_{C}}=C_{L_{C}} \frac{1}{2} \alpha_{i_{\infty}}
$$

The shaft power is given by

$$
P_{\text {shaft }} \eta_{p}=\frac{1}{2} \rho V_{\infty}^{3} S\left(C_{E}-C_{Q}\right)
$$

where $\eta_{p}$ is the propeller overall efficiency. For compatibility with the GP formulation, the $C_{Q}$ term was neglected. This is typically an order of magnitude smaller than $C_{E}$ for jets where $V_{J} \gg V_{\infty}$.

For large deflections of the flap, some of the assumptions in this model start to break down. Apart from the small angle assumptions, the model assumes that the jet is turned completely by the flap with no separation. This may not be realistic for large values of $\delta_{f}$, where viscous separation at the trailing edge is likely, especially if the flap is relatively sharply curved. This motivates the development of the second flap model.

\section{Split Jet}

The previous formulation can be readily extended to the case where the jet separates off the upper surface of the wing, shown in Figure 6. The ratio of blowing between the upper and lower surfaces is controlled by a parameter $f_{\text {jet }}$. $f_{\text {jet }}=1$ corresponds to only upper surface blowing, and $f_{\text {jet }}=0$ corresponds to only a deflected slipstream. This changes the effective height of the upper and lower jets, and consequently 
the effective jet blowing coefficients. Assuming the density and velocity are constant across the jet, the relationship between $f_{\text {jet }}$ and the top and bottom jet heights are shown below.

$$
\begin{gathered}
h_{\text {upper }}=h_{\text {jet }} f_{\text {jet }} \\
h_{\text {lower }}=h_{\text {jet }}\left(1-f_{\text {jet }}\right) \\
C_{J_{\text {upper }}}=C_{J} f_{\text {jet }} \\
C_{J_{\text {lower }}}=C_{J}\left(1-f_{\text {jet }}\right)
\end{gathered}
$$

Only the upper surface blowing is assumed to modify the lift due to circulation, as described in the previous section. The upper surface jet is not assumed to be turned by the flap, but it does have a small jet turning angle which is the angle of the airfoil upper surface trailing edge with respect to the mean chord line. For a typical airfoil this is about $10^{\circ}$.

The lower jet is assumed to exit the control volume at the same angle as the initial jet deflection. The lift and streamwise force equations (35) and (34)then become

$$
\begin{gathered}
C_{L}=C_{L_{C}}+C_{J_{\text {upper }}} \sin \alpha_{i_{\infty}}+C_{J_{\text {lower }}} \sin \delta_{f} \\
C_{X}=C_{L_{C}} \alpha_{i}-C_{J_{\text {lower }}} \cos \delta_{f}-C_{J_{\text {upper }}} \cos \alpha_{i_{\infty}}+2 C_{Q}+C_{D_{P}}
\end{gathered}
$$

The profile drag effects of this separation can be modeled to first order as a flat plate.

\section{B. GP Aircraft Equations}

The aircraft weight is comprised of the battery, payload, wing, motor, and structural weight,

$$
W_{\mathrm{MTO}} \geq W_{\mathrm{batt}}+N_{\mathrm{pax}} W_{\text {pax }}+W_{\text {wing }}+W_{\text {motor }}+W_{\text {struct }}
$$

where the motor, passenger, and structural weights are

$$
\begin{aligned}
W_{\text {motor }} & \geq \frac{P_{\text {shaft-max }}}{(P / W)_{\text {motor }}} \\
W_{\text {pax }} & =195[\mathrm{lbf}] \\
W_{\text {struct }} & \geq W_{\text {MTO }} f_{\text {struct }} .
\end{aligned}
$$

Passenger weight estimates are based on FAA guidance [34]. The battery weight is constrained by the range of the aircraft

$$
R \leq \frac{h_{\text {batt }} W_{\text {batt }} \eta_{\text {elec }} V}{g P_{\text {shaft }}}
$$

where the shaft power is

$$
P_{\text {shaft }} \geq \frac{T V}{\eta_{\text {prop }}}
$$

The aircraft is assumed to be in steady level flight during cruise.

The wing weight is composed of the skin, main spar and additional components

$$
\begin{aligned}
& W_{\text {wing }} \geq W_{\text {skin }}+W_{\text {spar }}+W_{\text {fadd }} \\
& W_{\text {fadd }} \geq 1.3 W_{\text {wing }}
\end{aligned}
$$

Where fadd accounts for the required weight of flaps, slats, and additional structural components. The skin and structural elements are assumed to be carbon fiber. The wing spar configuration is a cap spar with unidirectional carbon fiber caps wrapped in a shear web as shown in Figure 14.

The spar dimensions are sized such that the material stresses are not exceeded under a $4 \mathrm{~g}$-load, 


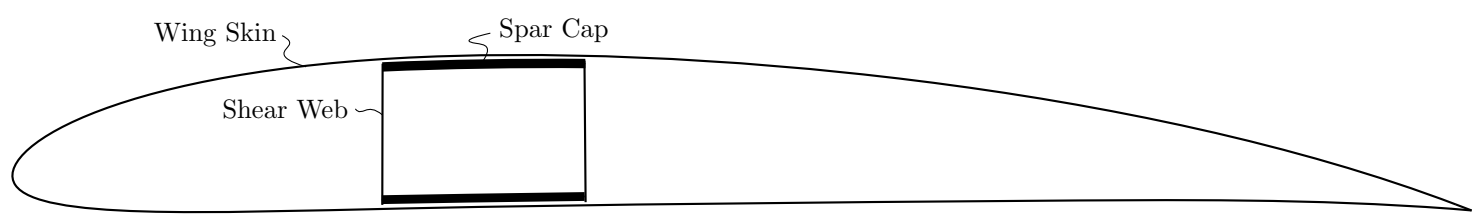

Figure 14: Cross sectional view of a cap spar.

$$
\sigma_{\mathrm{CFRP}} \geq \frac{\mathcal{M}_{\text {root }}}{S_{y_{\text {spar }}}}
$$

The root wing moment $\mathcal{M}_{\text {root }}$, is calculated assuming a distributed load along the wing span that scales with the local chord.[38] A constant tapered wing is assumed. This wing sizing model leverages the GP wing sizing model used by Burton and Hoburg.[32]

A simple drag model is used for the aircraft cruise performance,

$$
C_{D} \geq C D A+c_{d_{p}}+\frac{C_{L}^{2}}{\pi e A R} .
$$

where the profile drag coefficient $c_{d_{p}}\left(C_{L}, R e\right)$, is calculated from a representative wing polar. The combined drag and wing loading models allow the aspect ratio to be optimized, trading structural weight with aerodynamic performance.

\section{Acknowledgments}

The authors would like to thank Mark Drela for his guidance in formulating the jet flap aerodynamic models, and the MIT Spring 201816.82 class for their visualizations of the aircraft.

\section{References}

1 Vascik, P. D., Systems-Level Analysis of On Demand Mobility for Aviation, Master's thesis, Massachusetts Institute of Technology, Department of Aeronautics and Astronautics, 2017.

2 Uber, "Fast-Forwarding to a Future of On-Demand Urban Air Transportation," 2016, From https://www.uber.com/elevate.pdf. Accessed Oct. 2017.

3 Perry, D., "AW609 certification slips again to end-2019," https://www.flightglobal.com/news/articles/aw609certification-slips-again-to-end-2019-446030/, Accessed: 2018-05-03.

4 Courtin, C. and Hansman, R. J., "Safety Considerations in Emerging Electric Aircraft Architectures," AIAA Aviation Forum, American Institute of Aeronautics and Astronautics, 2018.

${ }^{5}$ Kurtz, D. W. and Marte, J. E., "A review of aerodynamic noise from propellers, rotors, and lift fans," Tech. rep., National Aeronaustics and Space Administration, Jan 1970.

6 Viken, S. A., Brooks, F. M., and Johnson, S. C., "Overview of the Small Aircraft Transportation System Project Four Enabling Operating Capabilities," Journal of Aircraft, Vol. 43, No. 6, nov 2006, pp. 16021612.

7 Holmes, B. J., Durham, M. H., and Tarry, S. E., "Small Aircraft Transportation System Concept and Technologies," Journal of Aircraft, Vol. 41, No. 1.

8 Harish, A., Perron, C., Bavaro, D., Ahuja, J., Ozcan, M. D., Justin, C. Y., Briceno, S., German, B. J., and Mavris, D., "Economics of Advanced Thin-Haul Concepts and Operations," 16th AIAA Aviation Technology, Integration, and Operations Conference, American Institute of Aeronautics and Astronautics, Washington, DC, June 2016. 
9 Kreimeier, M., Stumpf, E., and Gottschalk, D., "Economical assessment of air mobility on demand concepts with focus on Germany," 16th AIAA Aviation Technology, Integration, and Operations Conference, AIAA Aviation Forum, American Institute of Aeronautics and Astronautics, June 2016.

10 Justin, C. Y., Payan, A. P., Briceno, S. I., and Mavris, D. N., "Operational and Economic Feasibility of Electric Thin Haul Transportation," 17th AIAA Aviation Technology, Integration, and Operations Conference, American Institute of Aeronautics and Astronautics, Reston, Virginia, Jun 2017.

11 Duffy, M. J., Wakayama, S., Hupp, R., Lacy, R., and Stauffer, M., "A Study in Reducing the Cost of Vertical Flight with Electric Propulsion," .

12 Antcliff, K. R., Moore, M. D., and Goodrich, K. H., "Silicon Valley as an Early Adopter for On-Demand Civil VTOL Operations," 16th AIAA Aviation Technology, Integration, and Operations Conference, AIAA Aviation Forum, American Institute of Aeronautics and Astronautics, June 2016.

13 Seeley, B. A., "Regional Sky Transit IV: Pocket Airpark Design Constraints," 17th AIAA Aviation Technology, Integration, and Operations Conference, American Institute of Aeronautics and Astronautics, Reston, Virginia, jun 2017.

14 MassGIS Data, "MassGIS Data - Building Structures (2-D, from Ortho Imagery)," http://www.mass.gov/anf/research-and-tech/it-serv-and-support/application-serv/office-of-geographicinformation-massgis/datalayers/structures.html, 2017.

15 EGIS3 LA County, "LARIAC2 Buildings," https://egis3.lacounty.gov/dataportal/2016/11/03/countywidebuilding-outlines-2014-update-public-domain-release/, 2008.

16 National Aeronautics and Space Administration, "NASA's X-57 Electric Research Plane," https://www.nasa.gov/image-feature/nasas-x-57-electric-research-plane, 2016, Accessed: 2017-12-10.

17 Stoll, A. M., Bevirt, J., Moore, M. D., Fredericks, W. J., and Borer, N. K., "Drag Reduction Through Distributed Electric Propulsion," 14th AIAA Aviation Technology, Integration, and Operations Conference, American Institute of Aeronautics and Astronautics, Reston, Virginia, jun 2014.

18 Borer, N. K., Patterson, M. D., Viken, J. K., Moore, M. D., Bevirt, J., Stoll, A. M., and Gibson, A. R., "Design and Performance of the NASA SCEPTOR Distributed Electric Propulsion Flight Demonstrator," 16th AIAA Aviation Technology, Integration, and Operations Conference, American Institute of Aeronautics and Astronautics, Reston, Virginia, jun 2016.

19 Moore, M. D., "Misconceptions of Electric Aircraft and their Emerging Aviation Markets," 52nd Aerospace Sciences Meeting, American Institute of Aeronautics and Astronautics, Reston, Virginia, jan 2014.

20 Siegel, D., Development of an Autoland System for General Aviation Aircraft, Master's thesis, Massachusetts Institute of Technology, Department of Aeronautics and Astronautics, 2012.

21 Maskell, E. C. and Spence, D. A., "A Theory of the Jet Flap in Three Dimensions," Proceedings of the Royal Society A: Mathematical, Physical and Engineering Sciences, Vol. 251, No. 1266, jun 1959, pp. 407-425.

22 Deere, K. A., Viken, S. A., Carter, M. B., Viken, J. K., Wiese, M. R., and Farr, N., "Computational Analysis of Powered Lift Augmentation for the LEAPTech Distributed Electric Propulsion Wing," AIAA, Vol. 5, No. 1.

23 Stoll, A. M., "Comparison of CFD and Experimental Results of the LEAPTech Distributed Electric Propulsion Blown Wing," 15th AIAA Aviation Technology, Integration, and Operations Conference, American Institute of Aeronautics and Astronautics, Reston, Virginia, jun 2015.

${ }^{24}$ Roe, M. H. and Renselaer, D. J., "STOL Tactical Aircraft Investigation, Externally Blown Flap. Volume II. Design Compendium," Tech. rep., Rockwell International Corporation, 1973.

25 McCormick, B. W., Aerodynamics of V/STOL Flight, Academic Press, 1967. 
${ }^{26}$ Kokam, "KOKAM Li-ion/Polymer Cell Superior Lithium Polymer Battery (SLPB)," http://kokam.com/data/Kokam_Cell_Brochure_V.4.pdf, Accessed: 2018-05-15.

27 Howard, C. E., "Uber defines Uber Elevate mission, vehicle requirements - Intelligent Aerospace," http://www.intelligent-aerospace.com/articles/2018/05/uber-defines-uber-elevate-missionvehicle-requirements.html, Accessed: 2018-05-15.

28 Patterson, M. D. and Borer, N. K., "Approach Considerations in Aircraft with High-Lift Propeller Systems," 17th AIAA Aviation Technology, Integration, and Operations Conference, American Institute of Aeronautics and Astronautics, Reston, Virginia, jun 2017.

29 Drela, M., "Powered Lift and Drag Calculations," Lecture Notes, 2018.

30 Warren Hoburg, P. K., "Data fitting with geometric-programming-compatible softmax functions," Optimization and Engineering, 2016.

31 Boyd, S., S., K., L., V., and Hassibi, A., "A Tutorial on Geometric Programming," Optimization and Engineering, Vol. 8, No. 1, 2007, pp. 67-127.

32 Burton, M. and Hoburg, W., "Solar and Gas Powered Long-Endurance Unmanned Aircraft Sizing via Geometric Programming," Journal of Aircraft, 2017.

${ }^{33}$ Hoburg, W. and Abbeel, P., "Geometric Programming for Aircraft Design Optimization," AIAA, 2014.

34 Federal Aviation Administration, "Advisory Circular 120-27E Aircraft Weight and Balance Control," 2005.

35 Raymer, D. P. and P., D., Aircraft Design : A Conceptual Approach, American Institute of Aeronautics and Astronautics, 2006.

36 ASTM, "Standard Practice for Safety Assessment of Systems and Equipment in Small Aircraft," ASTM F3179-16, ASTM International, West Conshohocken, PA, 2016.

37 Federal Aviation Administration, "Pilot Guide to Takeoff Safety," https://www.faa.gov/other_visit/aviation_industry/airline_operators/training/media/takeoff_safety.pdf.

38 Drela, M., "Wing Bending Calculations," https://ocw.mit.edu/courses/aeronautics-and-astronautics/1601-unified-engineering-i-ii-iii-iv-fall-2005-spring-2006/systems-labs-06/spl10.pdf. 